\title{
Enantioseparation of P-Stereogenic Secondary Phosphine Oxides and Their Stereospecific Transformation to Various Tertiary Phosphine Oxides and a Thiophosphinate
}

\author{
Bence Varga, Péter Szemesi, Petra Nagy, Réka Herbay, Tamás Holczbauer, Elemér Fogassy, \\ György Keglevich, and Péter Bagi*
}

Cite This: J. Org. Chem. 2021, 86, 14493-14507

Read Online

ABSTRACT: Secondary phosphine oxides incorporating various aryl and alkyl groups were synthesized in racemic form, and these products formed the library reported in this study. TADDOL derivatives were used to obtain the optical resolution of these $P$-stereogenic secondary phosphine oxides. The developed resolution method showed a good scope under the optimized reaction conditions, as 9 out of 14 derivatives could be prepared with an enantiomeric excess (ee) $\geq 79 \%$ and 5 of these derivatives were practically enantiopure $>\mathrm{P}(\mathrm{O}) \mathrm{H}$ compounds (ee $\geq 98 \%$ ). The scalability of this resolution method was

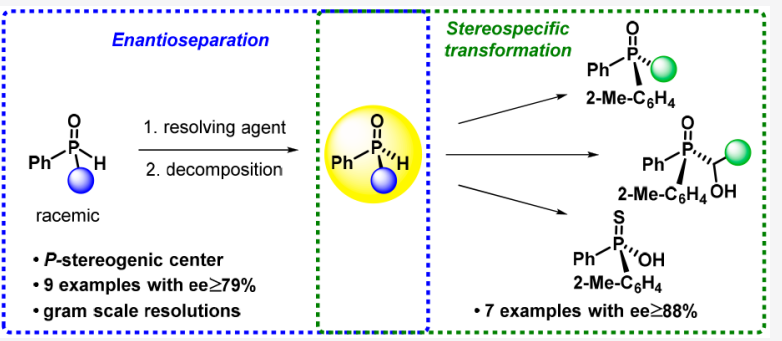
also demonstrated. Noncovalent interactions responsible for the formation of diasteromeric complexes were elucidated by single-crystal XRD measurements. ( $S$ )-(2-Methylphenyl)phenylphosphine oxide was transformed to a variety of $P$-stereogenic tertiary phosphine oxides and a thiophosphinate in stereospecific MichaelisBecker, Hirao, or Pudovik reactions.

\section{INTRODUCTION}

P-Stereogenic phosphines, phosphine oxides, or phosphonium salts represent an important class among organophophorus compounds, as these chiral derivatives have found widespread application as ligands, ${ }^{1}$ organocatalysts, ${ }^{2}$ or even biologically active compounds. ${ }^{3}$ The preparation of enantiopure $P$ compounds still represents a challenge, which inhibits their more diverse use. Most of the synthetic methods give the organophosphorus compound of interest in optically active form. ${ }^{4}$ Syntheses involving the preparation of $P$-chiral precursors followed by their incorporation in the desired scaffold represent a modular strategy carrying high synthetic potential. Bench stability, low toxicity, odorless property, and the stereospecific functionalization of their $\mathrm{P}-\mathrm{H}$ bond make secondary phosphine oxides (SPOs) desired P-stereogenic precursors. ${ }^{5}$ Moreover, when the $>\mathrm{P}(\mathrm{O}) \mathrm{H}->\mathrm{P}(\mathrm{OH})$ tautomerization is utilized, ${ }^{6}$ secondary phosphine oxides can be regarded as (pre)ligands, which can be used in transition metal catalyzed asymmetric transformations. ${ }^{7}$

These properties make $P$-stereogenic SPOs valuable targets, and a variety of stereoselective syntheses or enantioseparation methods have been developed in recent years. ${ }^{8}$ Most of the stereoselective syntheses rely on nucleophilic substitution of enantiopure $H$-phosphinates (Figure 1A). The mode of preparation of the chiral $H$-phosphinate is a key difference between the given methods. Menthyl and later adamantyl phenyl- $H$-phosphinate were among the first simple optically active $H$-phosphinates used for stereoselective synthesis of chiral SPOs. Separation of the corresponding racemic compounds was used for the preparation of optically active $H$-phosphinate starting materials, and these studies also highlighted that undesired racemization may happen during nucleophilic substitution when certain organometallic reagents are used. ${ }^{9}$ Another strategy utilizes amino-alcohols as chiral templates, and hydrolysis of the chiral oxazaphospholidine intermediate gives the corresponding $\mathrm{H}$-phosphinates, which are then reacted with organometallic reagents. ${ }^{10}$ Despite the advantages of the stereoselective syntheses, carefully controlled reaction conditions were required for each of the three key steps in order to avoid partial racemization and to obtain secondary phosphine oxides with high enantiomeric purity. In contrast, racemic secondary phosphine oxides can be prepared in just two steps considering the most straightforward synthetic path. $^{11}$

Thus, various separation methods of the corresponding racemates represent alternative methods for the preparation of optically active SPOs. In recent years, a few kinetic resolutions were developed employing chiral catalysts to give various

Received: June 9, 2021

Published: October 11, 2021 

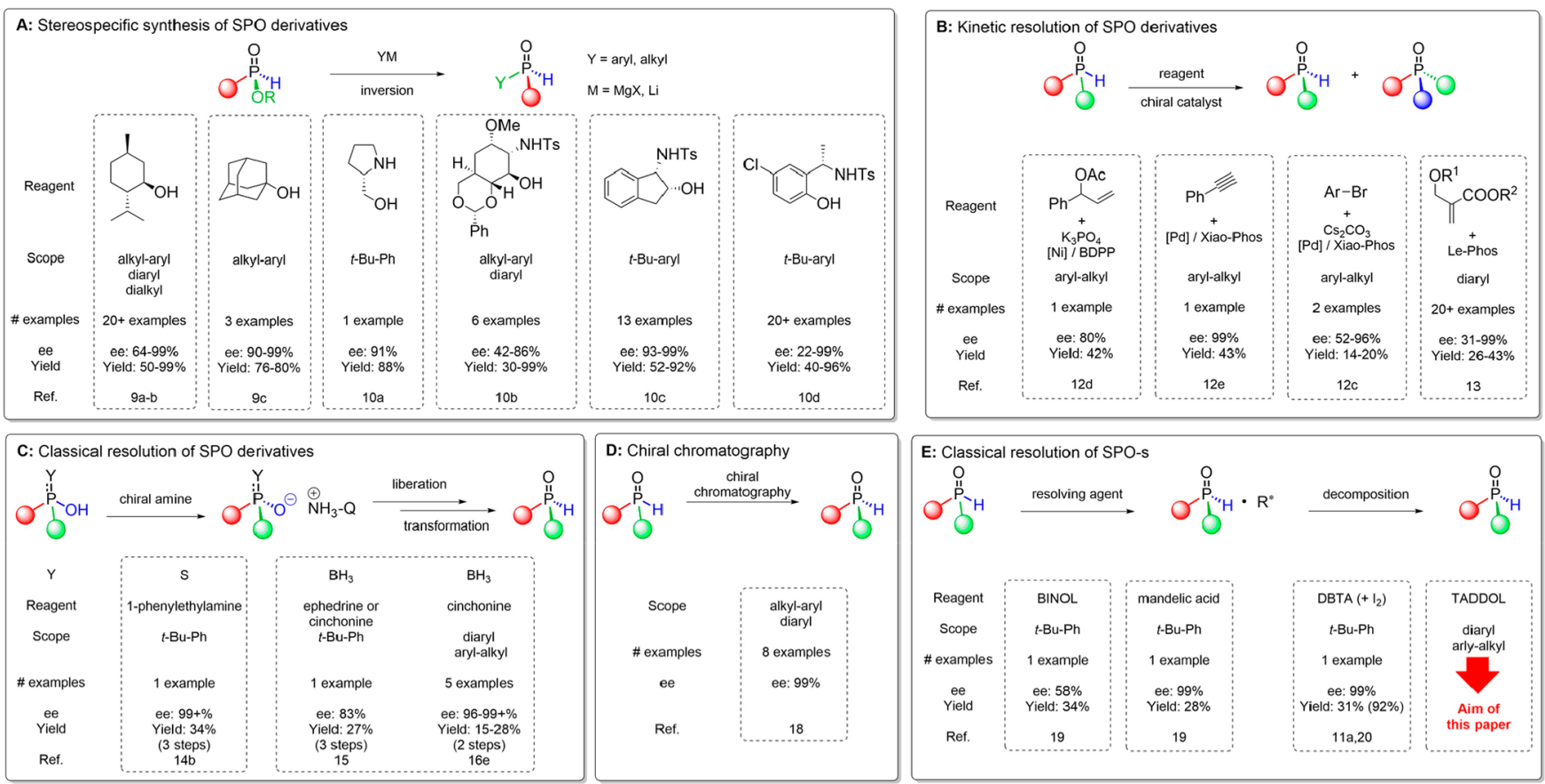

Figure 1. Selected examples showing the main methods for the preparation of $P$-stereogenic secondary phosphine oxides in optically active form (yields were calculated on the basis of the full amount of the racemate).

$P$-stereogenic tertiary phosphine oxides with excellent enantiomeric excesses (ee's). ${ }^{12}$ In theory, such reactions would give the unreacted portion of the SPO with high enanantiomeric purity (Figure 1B). However, optically active SPOs were seldom isolated from the corresponding reaction mixtures, ${ }^{12 \mathrm{c}-\mathrm{e}}$ and a few mechanistic studies revealed that optically active SPOs may racemize to some extent under the reaction conditions. ${ }^{12 \mathrm{~b}-\mathrm{d}}$ In a recent publication, Zhang and co-workers demonstrated an organocatalytic kinetic resolution using chiral phosphine catalysts. Besides the TPO products, the corresponding optically active SPOs were also isolated in good to excellent ee-s, showing a wide scope among $P$ stereogenic diaryl secondary phosphine oxides. ${ }^{13}$

Classical resolutions, which are based on the formation and separation of crystalline diastereomeric salts or complexes, were among the first few methods developed for the enantioseparation of $P$-stereogenic secondary phosphine oxides. It is noteworthy that $t$-butyl-phenylphosphine oxide was the main focus of those studies. One type of resolution method involves the transformation of SPOs to the corresponding thiophosphinic acids or phosphinous acidboranes. The enantioseparation of these acidic derivatives was elaborated with chiral bases, and optically active SPOs were obtained after the removal of the sulfur or borane. Haynes et al. used this reaction sequence for the preparation of enantiopure $t-\mathrm{Bu}(\mathrm{Ph}) \mathrm{P}(\mathrm{O}) \mathrm{H}$ in multigram quantities via a thiophosphinic intermediate, ${ }^{14}$ whereas the phosphinous acidborane route was explored by Stankevic and Pietrusiewicz. ${ }^{15}$ There are a few other reports detailing the resolution of the acidic derivatives of other SPOs, but deprotection is generally omitted in those studies. ${ }^{16}$ These optical resolution methods comprise two additional steps, which potentially lower the yield and increase the risk of undesired racemization (Figure 1C). ${ }^{15,17}$ Enantiomeric separation without derivatization is a more straightforward approach to obtain optically active secondary phosphine oxides. Chromatographic separation using chiral stationary phases was used to prepare the enantiomers of chiral SPOs on a small scale (Figure 1D). ${ }^{18}$ Considering classical resolutions of secondary phosphine oxides, enantiopure $t$-butyl-phenylphosphine oxide could be prepared using mandelic acid or $O, O^{\prime}$-dibenzoyltartaric acid (DBTA) as the resolving agents, ${ }^{11 a, 19}$ and partial enantiomeric separation was achieved with BINOL $^{19}$ or chalcone sulfonic acid. $^{11 a}$ Minnaard and co-workers found that the radical racemization of $t-\mathrm{Bu}(\mathrm{Ph}) \mathrm{P}(\mathrm{O}) \mathrm{H}$ could be promoted using a catalytic amount of iodine. When this racemization process was implemented into the optical resolution with $O, O^{\prime}$-dibenzoyltartaric acid, a dynamic resolution procedure was developed, which afforded nearly full conversion of the racemate to $(R)-t-\mathrm{Bu}(\mathrm{Ph}) \mathrm{P}(\mathrm{O}) \mathrm{H}$ with high enantiomeric purity. ${ }^{20}$ Despite these promising results, such direct resolutions have never been extended to other secondary phosphine oxides, leaving the enantiomers of $t$-butyl-phenylphosphine oxide as the sole example prepared by this method (Figure 1E).

This summary shows that renewed interest in $P$-stereogenic SPOs populated especially the stereoselective or kinetic resolution methods, whereas the number of classical resolutions still remains low with limited scope. One of our ongoing interests involves the preparation of chiral organophosphorus compounds, and the high synthetic potential of $P$ stereogenic SPOs prompted us to develop enantiomeric separation methods for this compound class. To date, only tertiary phosphine oxides were made available in optically active form by our resolution methods. ${ }^{21}$ The elaboration of such a method for $P$-stereogenic SPOs is not straightforward, as one of the TPO functional groups capable of the formation of secondary interactions is replaced by a proton, which makes the enantiomeric recognition and the separation of SPOs challenging.

The aim of this research was to develop a versatile enantioseparation method for the preparation of optically active secondary phosphine oxides (1). On the one hand, 
diaryl secondary phosphine oxides $(\mathbf{1} \mathbf{a}-\mathbf{i})$ containing substituents in the ortho-, meta-, or para-position were our focus in order to investigate the effect of the substitution pattern on the efficiency of the enantiomeric separation and to increase the number of separation methods for such SPOs. On the other hand, alkyl-aryl derivatives $(\mathbf{1} \mathbf{j}-\mathbf{n})$ were also included in this study in order to investigate the general scope of our resolution method. The secondary interactions within the diastereomers were investigated by single crystal X-ray crystallography. Starting from a selected secondary phosphine oxide, the synthesis of various optically active $P$-stereogenic tertiary phosphine oxides and thiophosphinates were attempted using stereospecific transformations (Figure 2).

(R,R)-2
14 examples
$Y^{1}=$ aryl or alkyl
$Y^{2}=$ alkyl, aryl, $\mathrm{SH}$ or $\mathrm{CH}(\mathrm{OH}) \mathrm{R}(\mathrm{R}=\mathrm{H}$ or $\mathrm{Ph})$

Figure 2. Outline of this research project.

\section{RESULTS AND DISCUSSION}

A synthetic strategy employing the diethylamino protecting group was selected for the synthesis of the racemic diaryl phosphine oxides $(\mathbf{1 a - i})$ (Scheme 1$)$. First, $P, P$-dichlorophenylphosphine (4) was reacted with diethylamine, and pure $N, N$-diethylamino-chloro-phenylphosphine (6) could be isolated by vacuum distillation. $N, N$-Diethylamino-chloro-phenylphosphine (6) was the key intermediate in our divergent synthetic strategy, and it was reacted with aryllithiums to give the corresponding aminophosphines (7). Then, the toluene solution of the protected intermediate (7) was treated with cc. $\mathrm{HCl}$ (aq.) in order to remove the diethylamino group and to facilitate hydrolysis to give the corresponding secondary phosphine oxides $(\mathbf{1} \mathbf{a}-\mathbf{i})$. The overall yield of this reaction sequence $(1 \mathbf{a}-\mathbf{i})$ was in between $42 \%$ and $77 \%$ after a final purification by column chromatography. This one pot strategy for the aminophosphine SPO transformation was first demonstrated by Hoge et al., ${ }^{22}$ and it has advantages over other literature procedures in which the removal of the protecting group and the hydrolysis of the intermediate are performed in two separate steps. ${ }^{23}$ The racemic alkyl-aryl secondary phosphine oxides $(\mathbf{1} \mathbf{j}-\mathbf{n})$ were prepared according to a literature procedure by reacting $\mathrm{PhPCl}_{2}$ with ethanol and treating the in situ formed ethyl phenyl- $\mathrm{H}$-phosphinate with the corresponding organometallic reagent. ${ }^{12 \mathrm{~b}, 24}$
With the racemic secondary phosphine oxides (1) in hand, we began our investigation to find a suitable resolving agent. Our previous research ${ }^{21 a-c}$ suggested that TADDOL derivatives might be good candidates for the optical resolution of the target secondary phosphine oxides (1). From our SPO library, the (2-methylphenyl)-phenylphosphine oxide (1a) was selected as the model racemic compound, and its resolution was attempted by various TADDOL derivatives and in a variety of solvents or solvent mixtures selected on the basis of our previous study (see the Supporting Information for details) (Scheme 2). ${ }^{21 \mathrm{c}}$ Even the first few experiments suggested that spiro-TADDOL $[(R, R)-2]$ is the most suitable resolving agent, as a change either in the aromatic groups or in the dioxolane ring of the TADDOL scaffold led to a significant decrease in the enantioseparation of secondary phosphine oxide 1a. Considering the solvents and the crystallization techniques, a precipitation-mediated crystallization from a mixture of toluene and hexane and a "classical" crystallization from 2$\mathrm{PrOH}$ were the two methods that showed the most promising results affording the (S)-(2-methylphenyl)-phenylphosphine oxide $[(S)-1 \mathrm{a}]$ in an ee above $95 \%$. The other solvents investigated gave significantly lower ee values and yields (see the Supporting Information for details).

Considering the scope of the secondary phosphine oxides (1), diaryl SPOs incorporating either a moderately electron donating methyl group or a strong electron withdrawing trifluoromethyl group in the ortho-, meta-, or para-position were investigated $(\mathbf{1 a}-\mathbf{f})$. Moreover, 1-naphthyl-, 2-methoxyphenyl, and (2-phenylphenyl)-phenylphosphine oxides (1gi) were also included in the study. Considering the alkylphenylphospine oxide derivatives $(\mathbf{1} \mathbf{j}-\mathbf{n})$, normal, branched, and cycloalkyl groups along with the benzyl group were selected in order to represent a variety of alkyl chains.

On the basis of the results of the preliminary studies, the optical resolution of all target secondary phosphine oxides (1) was attempted with spiro-TADDOL $[(R, R)-2]$ using either 2propanol or a mixture of toluene and hexane as the solvent. It was found that even traces of water in the solvent cause inconsistent results; for this, dry solvents were used during the crystallization of the diastereomers. In all resolution experiments, the diastereomeric complexes were purified by recrystallization(s) in order to increase the diastereomeric purity. The given enantiomerically enriched secondary phosphine oxide (1) was liberated from the diastereomeric complexes by column chromatography, and the resolving agent $[(R, R)-2]$ could also be recycled. Our previous study showed that organic solvent nanofiltration could be a scalable alternative process of such decompositions and recycling. ${ }^{21 c}$ Most of the resolution experiments were attempted according to half-equivalent and equivalent methods in order to

Scheme 1. Preparation of Racemic Diaryl Secondary Phosphine Oxides (1a-i)

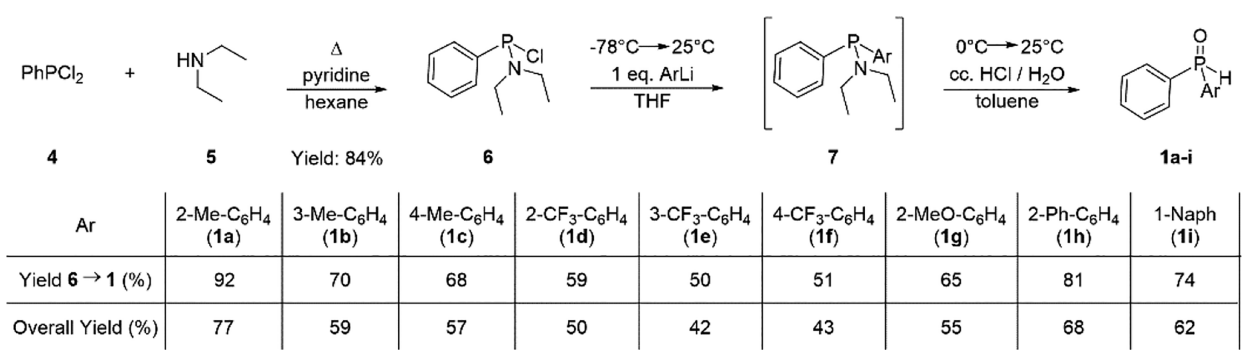


Scheme 2. Summary of the Best Results for the Resolution of $P$-Stereogenic Secondary Phosphine Oxides $(1)$ with $(R, R)$-spiroTADDOL $[(R, R)-2]$
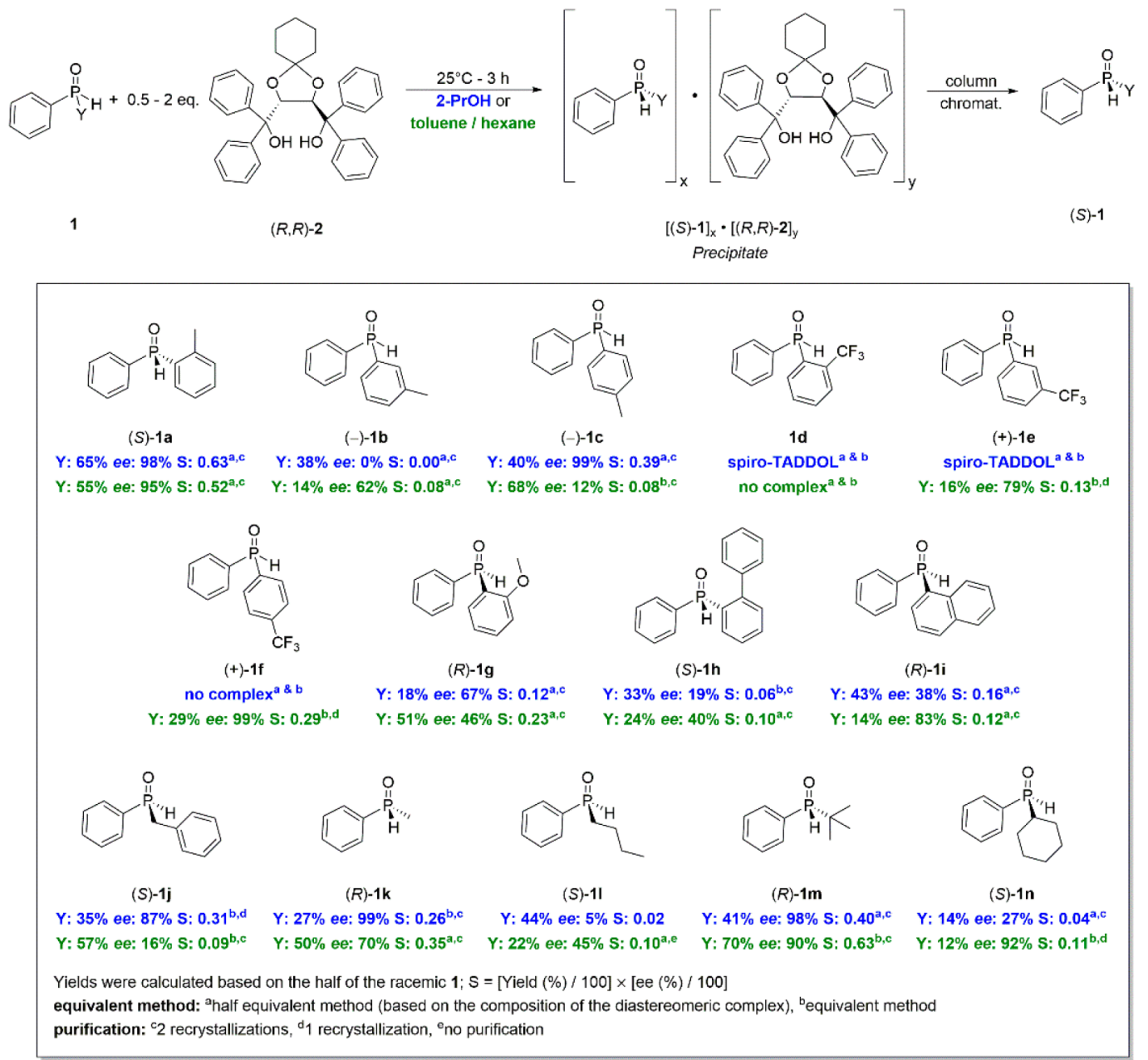

investigate which separation method is the more effective one. Thus, the amount of spiro-TADDOL $[(R, R)-2]$ varied between 0.5 and 2 equiv, depending on the composition of the diastereomeric complex formed (vide infra). Results are summarized in Scheme 2 (see the Supporting Information for the complete set of experimental data).

The results indicated that the position and the nature of the substituent significantly influence the efficiency of the enantiomeric separation. Beside (2-methylphenyl)-phenylphosphine oxide (1a), the (4-methylphenyl) and (4-trifluoromethylphenyl) derivatives (1c and 1f) could be prepared in enantiopure form (ee: 99\%) in yields of $40 \%$ or $29 \%$, respectively. Interestingly, the enantiomers of (2-methylphenyl)-phenylphosphine oxide (1a) could be separated effectively (ee $>95 \%, S>0.52$ ) either in 2-propanol or in a mixture of toluene and hexane. On the other hand, only one of the two crystallization methods afforded pure enantiomers for the parasubstituted derivatives (1c and 1f). One may conclude that the substituent at the para-position has the least effect on the outcome of the resolution. A para-substituent is not in the proximity of the $>\mathrm{P}(\mathrm{O}) \mathrm{H}$ function; hence, it does not interfere with the mode of binding and noncovalent interactions formed between the given secondary phosphine oxide (1c or 1f) and spiro-TADDOL $[(R, R)-2]$.

In contrast, ortho- and meta-substituents in a phenyl ring have a more decisive role on the overall efficiency of the resolution. 3-Methyl- or (3-trifluoromethyl-phenyl)phenylphosphine oxide (1b and 1e) could be prepared with a maximum ee of $62 \%$ or $79 \%$, respectively. The yields were rather low (14-16\%), and consequently, the resolving capability values fell in the range of $0.08-0.13$. Considering the ortho-substituted derivatives (1a, 1d, 1g, and $\mathbf{1 h}$ ), the change of the methyl group of the racemic compound to a trifluoromethyl, methoxy, or phenyl group led to a decrease in enantiomeric excess $(0-67 \%)$ and in resolving capability values (0.00-0.23). The (2-trifluoromethylphenyl)-phenylphosphine oxide (1d) was the only derivative when the enantiomeric separation was completely unsuccessful, as no diastereomeric complex was formed. One may assume that the trifluoromethyl group being close to the $\mathrm{P}(\mathrm{O}) \mathrm{H}$ group lowers the Lewis basicity of the $\mathrm{P}=\mathrm{O}$ function; thus, the guest molecule (1d) loses its ability to form a stable $H$ bond with the resolving agent $[(R, R)-2]$ (vide infra). The methoxy group is another $\mathrm{H}$-bond acceptor, whereas the 2-phenylphenyl group significantly increases the steric bulk in the ortho-position. Each effect has a negative impact on the enantiomeric recognition and, consequently, on the efficiency of the resolution (ee $=67 \%$ and $S=0.12$ for $1 \mathrm{~g}$; ee $=40 \%$ and $S$ $=0.10$ for $\mathbf{l h}$ ).

Moderate results were obtained for (1-naphthyl)-phenylphosphine oxide (1i) (ee $=38 \%$ and $S=0.16$ or ee $=83 \%$ and $S=0.12$ ), which was another indication that increased steric 
Scheme 3. Gram-Scale Resolution of (2-Methylphenyl)-phenylphosphine Oxide (1a) and (t-Butyl)-phenylphosphine Oxide (1m) with $(R, R)$-spiro-TADDOL $[(R, R)-2]$

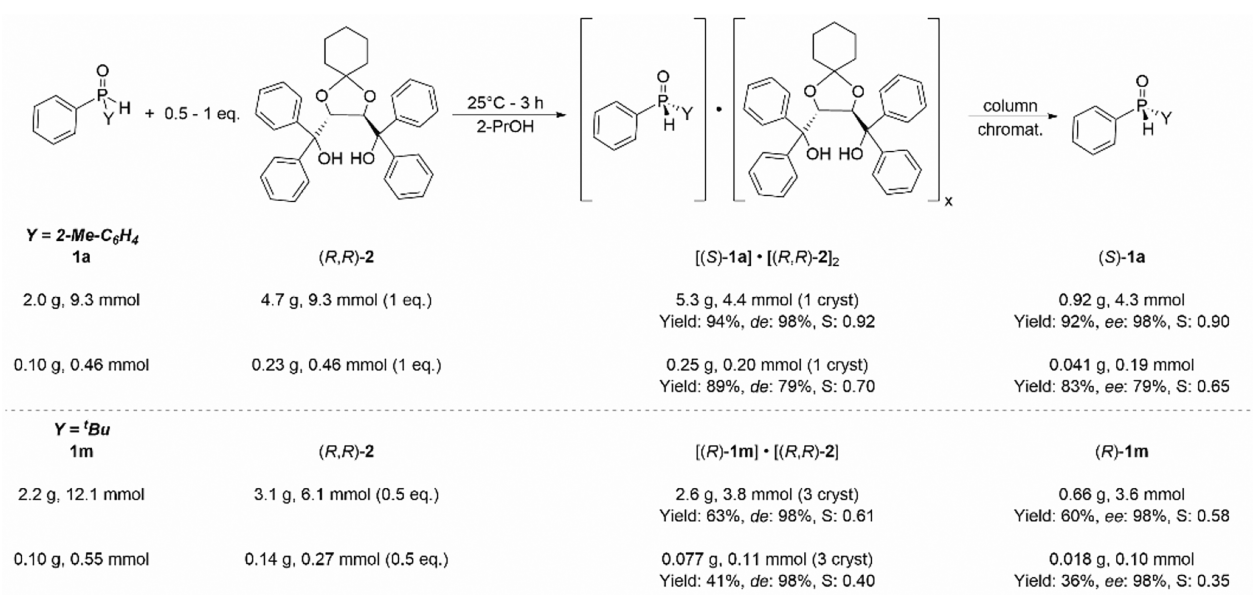

demand has a negative impact on the host-guest interactions and, consequently, on the overall efficiency of the resolution. Considering the alkyl-aryl secondary phosphine oxides $(\mathbf{1 j}-\mathbf{n})$, the selected derivatives could be resolved with good overall efficiency. Four $(\mathbf{1 j}, \mathbf{1 k}, \mathbf{1 m}$, and $\mathbf{1 n})$ out of the five derivatives could be prepared with an ee greater than $87 \%$, and the resolving capability values fell in the range of $0.11-0.63$. The $(S)$-methyl- or ( $t$-butyl)-phenylphoshine oxide $[(S)$-1k or $(S)$ $\mathbf{1 m}$ ] were the two derivatives that could be prepared in practically enantiopure form (ee > 98\%). These results indicated that the optical resolution with $(R, R)$-spiroTADDOL $[(R, R)-2]$ tolerated normal, cyclo, and aralkyl chains. The butyl-phenylphosphine oxide (11) was the only derivative that could not be separated effectively (ee $\leq 45 \%$; $S$ $\leq 0.10$ ). One underlying reason might be that the normal butyl chain cannot form stable second order interactions, whereas these contacts might be more pronounced for the more compact or sterically more demanding (cyclo)alkyl groups. The resolution of a few selected SPOs of special interest, such as the 2-methoxyphenyl-, 1-naphthyl-, and $t$-butyl-derivative $(1 \mathrm{~g}, 1 \mathrm{i}$, and $1 \mathrm{~m})$, was also attempted with two additional spiroTADDOL derivatives. The partial separation of the enantiomers was only successful in the case of the (1-naphthyl)phenylphosphine oxide (1i), but a lower enantiomeric excess value could be obtained with $\mathbf{1 i}$ (ee: 70\%) than with the spiroTADDOL $[(R, R)-2]$ (ee: $83 \%)$. These results show that better enantioseparation in this SPO library may not be obtained by changing the structure of the resolving agent (see Table S4 for details).

${ }^{1} \mathrm{H}$ NMR studies revealed that the composition of the diastereomeric complexes was dependent on the solvent used. Diastereomers incorporating the given secondary phosphine oxide enantiomer $(\mathbf{1})$ and $(R, R)$-spiro-TADDOL $[(R, R)-2]$ in a $1: 1$ ratio were formed in a mixture of toluene and hexane, whereas this SPO-spiro-TADDOL $[1-[(R, R)-2]$ ratio changed predominantly to 1:2 when 2-propanol was used as solvent. This change in the composition of the host-guest complexes indicates that the mode of binding and, consequently, the ratio of 1 and $[(R, R)-2]$ changes when the protic 2-propanol or the aprotic toluene-hexane mixture is used as solvent. The enantiopreference of the resolving agent $[(R, R)-2]$ was not solvent dependent, ${ }^{21 a}$ and the same secondary phosphine enantiomer $[(R)-\mathbf{1}$ or $(S)-1]$ was incorporated into the diastereomeric complex under both crystallization conditions. The absolute configuration of the secondary phosphine oxides $\mathbf{1 a}$ and $\mathbf{1 g}-\mathbf{n}$ was assigned according to literature data. ${ }^{9 \mathrm{~b}, 10 \mathrm{~b}, 14 \mathrm{~b}}$ Moreover, a single crystal $\mathrm{XRD}$ measurement has also confirmed the absolute configuration of (S)-1a (vide infra).

After the evaluation of the substrate scope of our resolution method, the scalability was assessed. A submillimolar scale (ca. $0.10 \mathrm{~g})$ was typically used for optimization, and the resolution of (2-methylphenyl)- and ( $t$-butyl)-phenylphosphine oxide (1a and $1 \mathrm{~m}$ ) were also elaborated on a gram scale (ca. $2 \mathrm{~g}$ of $1 \mathrm{a}$ or $\mathbf{1 m})$ using $(R, R)$-spiro-TADDOL $[(R, R)-2]$ as the resolving agent and $2-\mathrm{PrOH}$ as the solvent (Scheme 3 ). In both cases, the enantioseparation could be elaborated successfully on a gram scale affording $(S)$-1a and $(R)-1 \mathrm{~m}$ with an ee of $98 \%$. Similarly to the optimization experiments, three crystallizations of the corresponding diastereomer $(R)-\mathbf{1} \mathbf{m} \cdot($ spiro-TADDOL) were necessary to reach a high optical purity of $(R)-\mathbf{1 m}$, and the yield improved from $36 \%$ to $60 \%$. Intriguingly, the $(S)-(2-$ methylphenyl)-phenylphosphine oxide $[(S)$-1a] was obtained with an ee of $98 \%$ and in a yield of $92 \%$ ( $S$ : 0.90$)$ even after one crystallization and decomposition of the diastereomeric complex $(S)$-1a.(spiro-TADDOL $)_{2}$ by column chromatography. These results are somewhat better than the ones obtained after the first crystallization and decomposition of the corresponding diastereomer $\left[(S)-\mathbf{1 a} \cdot(\text { spiro-TADDOL })_{2}\right]$ during the preliminary studies (ee: $79 \%$; yield: $83 \%$; $: 0.65$ ). The larger scale allowed a more efficient crystallization and a better separation of the crystalline diastereomer from the mother liquor, which consequently led to a better yield in both cases and a more simple procedure for $(S)$-1a. It is noteworthy that the mother liquor of the optical resolutions contained the other SPO antipode $(R)-1$ a in excess. Enantiopure $(R)-1$ a could be obtained by the optical resolution of this mother liquor with $(S, S)$-spiro-TADDOL under the same crystallization conditions, as it was demonstrated in our previous studies. $^{21 \mathrm{a}, \mathrm{c}}$

The diastereomeric complex $(S)$-1a $\cdot($ spiro-TADDOL) (diastereomeric excess (de): 95\%) prepared from a mixture of toluene and hexane was selected for X-ray analysis, and the single crystals were grown from the same solvent mixture. The absolute configuration of $(S)$-(2-methylphenyl)-phenylphosphine oxide $[(S)-\mathbf{1 a}]$ was determined using the known absolute configuration of $(R, R)$-spiro-TADDOL $[(R, R)-2]$ as reference. The crystal lattice comprises the SPO $(S)-1$ a and the 
resolving agent $(R, R)-2$ in a $1: 1$ ratio, which is in accordance with our NMR measurements. A characteristic intramolecular $\mathrm{H}$ bond is present between the two $\mathrm{OH}$ groups of $(R, R)$-spiroTADDOL $[(R, R)-2]]^{21 \mathrm{a}, \mathrm{c}}$ and the $(S)-\mathbf{1 a}$ and $(R, R)-\mathbf{2}$ hostguest molecules are held together by an $\mathrm{O}-\mathrm{H} \cdots \mathrm{O}$ bridge (Figure 3). ${ }^{25}$ Energy calculations were conducted with the

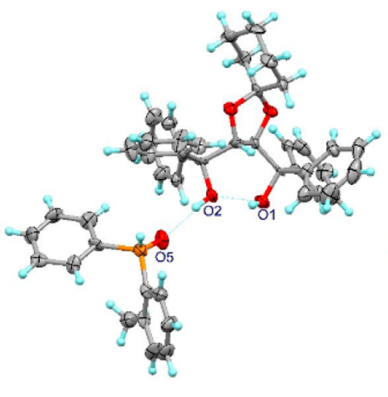

(a)

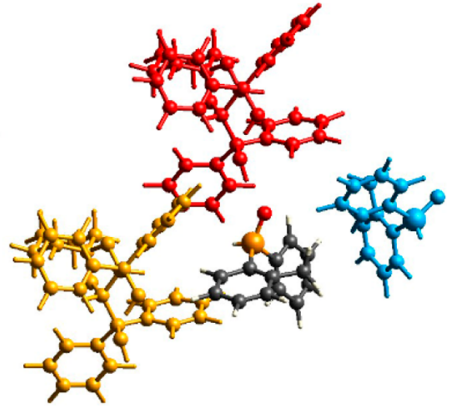

(b)
Figure 3. (a) Hydrogen bonds formed in the diastereomeric complex (S)-1a.(spiro-TADDOL). Nonhydrogen atom ellipsoids are drawn on a 30\% probability level. (b) The neighboring molecules with the strongest interactions of $(S)$-1a for the calculation of interaction energies (DFT calculation details can be found in Table 1).

Table 1. Calculated Total Energies for the Neighboring Molecules of $(S)-1 a^{b}$

\begin{tabular}{|l|l|l|l|l|l|l|l|}
\hline $\mathrm{N}$ & Symop & $\mathrm{R}^{\mathbf{2}}$ & $\mathrm{E}_{\text {ele }}$ & $\mathrm{E}_{\mathrm{pol}}$ & $\mathrm{E}_{\mathrm{dis}}$ & $\mathrm{E}_{\text {rep }}$ & $\mathbf{E}_{\text {tot }}$ \\
\hline$(R, R)-2$ & - & 7.66 & -62.7 & -17.6 & -28.9 & 71.6 & $\mathbf{- 6 0 . 3}$ \\
\hline $\begin{array}{l}(R, R)-2 \\
\# 2\end{array}$ & - & 7.17 & -11.7 & -4.8 & -43.3 & 22.4 & $\mathbf{- 3 9 . 9}$ \\
\hline$(S)-1 \mathrm{a} \# 2$ & $-\mathrm{x}, \mathrm{y}+\mathbf{1} / \mathbf{2},-\mathrm{z}$ & 6.30 & -14.4 & -3.5 & -36.7 & 32.3 & $\mathbf{- 2 9 . 7}$ \\
\hline
\end{tabular}

${ }^{a} R$ is the distance within the center of the molecules. ${ }^{b}$ The color of the first column corresponds to the color of the given molecules in Figure $3 \mathrm{~b}$.

Crystal Explorer program using the B3LYP/6-31G(d,p) level of theory (Table 1$).^{26}$ Total energies $\left(E_{\text {tot }}\right)$ were the sum of the Coulomb interactions $\left(E_{\text {ele }}\right)$, polar interactions $\left(E_{\text {pol }}\right)$, dispersion interactions $\left(E_{\mathrm{dis}}\right)$, and repulsive interactions $\left(E_{\mathrm{rep}}\right)$. The four energy components were scaled in the total energy
$\left(E_{\text {tot }}=1.019 E_{\text {ele }}+0.651 E_{\text {pol }}+0.901 E_{\text {dis }}+0.811 E_{\text {rep }}\right)$. Interaction energies were investigated for a $3.8 \AA$ cluster around the selected secondary phosphine oxide $(S)-1$ a. These DFT calculations also confirmed that the two $\mathrm{O}-\mathrm{H} \cdots \mathrm{O}$ interactions are the strongest ones in the crystal lattice (Table 1 and Figure 3 ). The second and third strongest interaction come from another neighboring $(R, R)$-spiro-TADDOL $[(R, R)-2]$ or $(S)$-(2-methylphenyl)-phenylphosphine oxide $[(S)-1 \mathrm{a}]$ molecule, respectively. The $\mathrm{O}-\mathrm{H} \cdots \mathrm{O}$ hydrophilic contact turns the $(R, R)-2$ and $(S)-1$ a molecules toward each other, creating a tight fit in between the host and guest molecules and creating a hydrophobic outer surface for this associate. Hirshfeld surface analysis also showed a high number of $\mathrm{H}$ contacts of the associated molecules. The $\mathrm{H}$ atom interactions corresponded to $84 \%$ of the intermolecular interactions, while the $\mathrm{O}$ atoms had a contribution of only $2.7 \%$ (see the Supporting Information for details). ${ }^{27}$

As the last step of this study, a few typical SPO transformations were also elaborated in order to prepare the corresponding tertiary phosphine oxides $[(S)-\mathbf{3} \mathbf{a}-\mathbf{d}]$, hydroxyphosphine-oxides $\left[(S)-3 \mathbf{f}\right.$ and $\left.\left(S_{\mathrm{P}}, R_{\mathrm{C}}\right)-\mathbf{3 g}\right]$, and a tiophosphonate $[(R)-3 \mathbf{e}]$ (Scheme 4$)$. Previously, such transformations were described using mainly the $t$-butyl-phenylphosphine oxide $(\mathbf{1 m})$ as the benchmark starting material. As the nature of the substituents may influence the $P$-inversion barrier, ${ }^{28}$ the $(S)$ (2-methylphenyl)phenylphosphine oxide $[(S)$-1a] with an ee of $98 \%$ was chosen as a diaryl-SPO model compound for these stereoselective transformations. One method for the preparation of $P$-stereogenic tertiary phosphine oxides is the alkylation of metalated secondary phosphine oxides (Michaelis-Becker reaction). ${ }^{14 \mathrm{~b}, 29}$ First, $(S)$-1a was added to the THF suspension of $\mathrm{NaH}$ at $0{ }^{\circ} \mathrm{C}$ to prepare $(2-\mathrm{MePh}) \mathrm{PhP}(\mathrm{ONa})$, and it was treated with the corresponding primary alkyl halide to give $(S)$ methyl-, ethyl- or benzyl-(2-methylphenyl)-phenylphosphine oxide $[(S)-3 \mathbf{a}-\mathbf{c}]$ in yields of $76-87 \%$. The enantiomeric purity of the tertiary phosphine oxides $(S)-\mathbf{3 a}-\mathbf{c}$ was in the range of $95-98 \%$, indicating high configurational stability of the secondary phosphine oxides and their deprotonated derivatives under the reaction conditions (Scheme 4A). Literature data suggested that this reaction proceeds with a retention at the $P$-stereogenic center. ${ }^{14 \mathrm{~b}, 29}$

Hirao coupling of $(S)$-(2-methylphenyl)-phenylphosphine oxide $[(S)-1$ a $]$ with 1-bromonaphtalene was also elaborated. Despite the popularity of this method for the formation of $\mathrm{P}-$

Scheme 4. Stereoselective Synthesis of Various P-Stereogenic Tertiary Phosphine Oxides and a Thiophosphinate (3) from $(S)$ (2-Methylphenyl)phenylphosphine Oxide [(S)-1a]
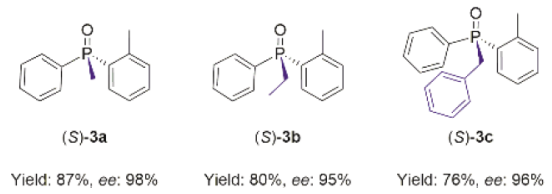

Yield: $87 \%$, ee: $98 \%$

Yield: $76 \%$, ee: $96 \%$
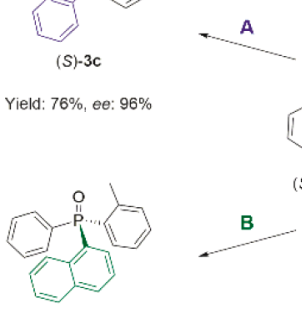

(S)-3d

Yield: $85 \%$, ee: $88 \%$

A: $0-25^{\circ} \mathrm{C}, 24 \mathrm{~h}, 1.3$ eq. $\mathrm{NaH}, 1.2 \mathrm{eq}$. Mel or $\mathrm{Etl}$ or $\mathrm{BnBr}$, abs. THF B: $110^{\circ} \mathrm{C}, 24 \mathrm{~h}, 5 \mathrm{~mol} \% \mathrm{Pd}\left(\mathrm{PPh}_{3}\right)_{4}, 1.1 \mathrm{eq}$. 1-Naph-Br, 2 eq. $\mathrm{K}_{2} \mathrm{CO}_{3}$ abs, toluene

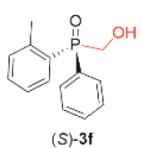

(S)-3f
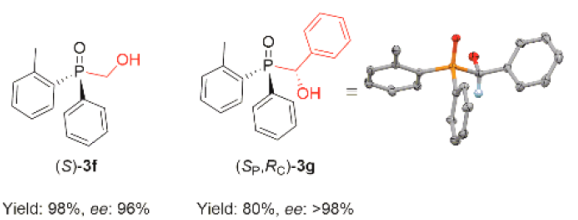

$\left(S_{\mathrm{P}}, R_{\mathrm{C}}\right)-3 \mathrm{~g}$

Yield: $80 \%$, ee: $>98 \%$

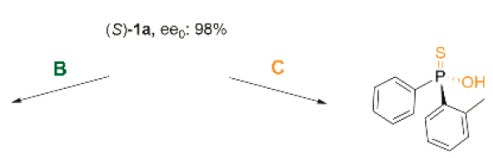

$(R)-3$

Yield: $80 \%, e^{\circ}>>98 \%$

C: $65^{\circ} \mathrm{C}, 1.5 \mathrm{~h}_{1} 1.0$ eq. $\mathrm{S}_{8}$, abs. THF

D: $80^{\circ} \mathrm{C}, 16 \mathrm{~h}, 1.2 \mathrm{eq} . \mathrm{CH}_{2} \mathrm{O}_{\text {(naj) }}$ or PhCHO, $0.05 \mathrm{M} \mathrm{NaOH}, \mathrm{H}_{2} \mathrm{O}$ 
$\mathrm{C}_{\mathrm{sp} 2}$ bonds, ${ }^{30}$ only a few reports can be found on the stereospecific arylation of $P$-stereogenic secondary phosphine oxides, ${ }^{10 c, 13,31}$ and the chiral SPOs might be prone to (partial) racemization under the reaction conditions. ${ }^{12 \mathrm{~b}}$ The $\mathrm{P}-\mathrm{C}$ cross coupling of $(S)$-1a was performed in toluene under reflux conditions in the presence of $\mathrm{Pd}\left(\mathrm{PPh}_{3}\right)_{4}$ using $\mathrm{K}_{2} \mathrm{CO}_{3}$ as the base, and these conditions were successfully applied for $t$ $\mathrm{BuPhP}(\mathrm{O}) \mathrm{H}$ (1m)..$^{31 \mathrm{~b}}(S)$-(1-Naphthyl)-(2-methylphenyl)phenylphosphine oxide $[(S)-3 \mathbf{d}]$ could be prepared with a yield of $85 \%$ and in an ee of $88 \%$. The high reaction temperature might be responsible for the partial racemization observed $\left(\mathrm{ee}_{0}=98 \% \rightarrow\right.$ ee $\left.=88 \%\right)$. This cross-coupling is expected to take place with retention of the $P$ absolute configuration (Scheme 4B). ${ }^{31}$

The addition of $(S)$-1a to formaldehyde or benzaldehyde was also studied in the presence of aq. $\mathrm{NaOH}$. The $(S)$ hydroxymethyl-(2-methylphenyl)-phenylphosphine oxide $[(S)-3 f]$ could be prepared in nearly quantitative yield (98\%) and with an ee of $96 \%$. The addition of benzaldehyde to $P$ stereogenic SPOs involves the formation of a new carbon stereogenic center. ${ }^{31} \mathrm{P}$ NMR spectra indicated that this reaction was highly diastereoselective, as the ratio of the two diastereomers was 97.5:2.5 in the crude product. Moreover, the $\left(S_{\mathrm{P}}, R_{\mathrm{C}}\right)$ enantiomer could be prepared with excellent enantiomeric purity (ee > 98\%) and in a yield of $80 \%$ (Scheme 4D). We believe that a crystallization induced asymmetric transformation is the underlying reason for this high diastereoselectivity. ${ }^{20,32}$ Crystalline product (3g) was immediately formed when $(S)$-1a was reacted with benzaldehyde at room temperature. The subsequent stirring of the aqueous suspension at $80^{\circ} \mathrm{C}$ for $16 \mathrm{~h}$ allows the dissolution of the more soluble diastereomer and its transformation to the less soluble stereoisomer via an equilibrium cascade, which involves a retro-Pudovik reaction in the supernatant. This hypothesis was supported by a few control experiments. When the reaction was performed either at a lower temperature or with shorter reaction times, a significant decrease in the diastereomeric excess of $3 \mathrm{~g}$ could be observed. As in the literature, ${ }^{33} \mathrm{X}$-ray crystallography was used for characterization. The XRD measurement of $\left(S_{\mathrm{P}}, R_{\mathrm{C}}\right)-\mathbf{3 g}$ confirmed that the reaction proceeds with retention of the $P$-configuration, which is in accordance with the literature. ${ }^{20,34}$ Moreover, the $(R)$ absolute configuration of the formed carbon stereogenic center could also be established. The neighboring hydroxy(phenyl)methyl(2-methylphenyl)-phenylphosphine oxides $\left[\left(S_{\mathrm{P}}, R_{\mathrm{C}}\right)-3 \mathrm{~g}\right]$ were held together by $\mathrm{H}$ bonds formed between $\mathrm{OH}$ and $\mathrm{P}=\mathrm{O}$ functional groups of two different $\left(S_{\mathrm{P}}, R_{\mathrm{C}}\right)-\mathbf{3 g}$ molecules (see the Supporting Information for details). ( $S$ )-1a was also reacted with elemental sulfur to prepare the corresponding thiophosphonic acid $3 \mathbf{e}$ with retention of the $P$-configuration (Scheme 4C). ${ }^{9 \mathrm{~b}, 16 \mathrm{~d}}$ Interestingly, the enantiomeric excess values of $3 \mathbf{g}$ could be determined by ${ }^{31} \mathrm{P}$ NMR using $(S)-1$ naphthylethylamine as a chiral solvating agent, as no chiral chromatographic method could be developed for $3 \mathrm{~g}$.

\section{CONCLUSIONS}

In conclusion, a series of $P$-stereogenic secondary phosphine oxides (1) was prepared in racemic form, and their enantiomeric separation was elaborated with $(R, R)$-spiroTADDOL $[(R, R)-2]$. The scope of the SPOs comprised several diaryl-derivatives containing a phenyl group and another aryl moiety with various substitution patterns $(\mathbf{1 a}-\mathbf{i})$ and alkyl-phenylphospine oxides $(\mathbf{1} \mathbf{j}-\mathbf{n})$ incorporating normal, branched, or cycloalkyl groups or a benzyl function. According to the preliminary experiments, the optical resolution of the target secondary phosphine oxides (1) was elaborated with $(R, R)$-spiro-TADDOL $[(R, R)-2]$ in 2-propanol or in a mixture of toluene and hexane. Nine derivatives $(\mathbf{1 a}, \mathbf{1 c}, \mathbf{1 e}, \mathbf{1 f}, \mathbf{1 i - k}$, $1 \mathbf{m}$, and $1 \mathbf{n}$ ) could be prepared with an ee $>79 \%$ (yield: $12-$ $65 \%$ ), and five of these derivatives (1a, 1c, 1f, $1 \mathrm{k}$, and $1 \mathrm{~m}$ ) were practically enantiopure secondary phosphine oxides (ee > $98 \%$, yield $27-65 \%$ ). To date, this current method has the widest scope among classical resolution methods developed for $P$-chiral secondary phosphine oxides. Our results indicated that substituents in the para-position of a phenyl group has the least effect on the overall efficiency of the resolution. On the contrary, an increased steric bulk, especially in the orthoposition, had a negative effect on the enantiomeric separation. Several alkyl-phenylphospine oxides $(\mathbf{1 j}, \mathbf{1 k}, \mathbf{1} \mathbf{m}$, and $\mathbf{1 n})$ containing various normal, cyclo, or aralkyl chains could be prepared with good enantiomeric purity and in acceptable yields (ee: $87-99 \%$; yield: $12-41 \%$ ). A gram-scale resolution of (2-methylphenyl)-phenylphosphine oxide (1a) was performed, indicating the scalability of this resolution method. Xray quality crystals were prepared from $(S)-\mathbf{1 a} \cdot($ spiroTADDOL), which was complemented with the DFT calculation to study the main interaction between the secondary phosphine oxide and the resolving agent.

Starting from $(S)$-(2-methylphenyl)-phenylphosphine oxide [(S)-1a] (ee: 98\%), several P-stereogenic phosphine oxides and a thiophosphonate (3) were prepared with excellent enantiomeric excess values (ee > 95\%). Only the Hirao coupling of secondary phosphine oxide $(S)$-1a with 1bromonaphtalene afforded (S)-(1-naphthyl)-(2-methylphenyl)-phenylphosphine oxide $[(S)-3 \mathbf{d}]$ with a somewhat lower optical purity (ee: $88 \%$ ), which could be attributed to the partial racemization of $(S)-\mathbf{1 a}$ at the elevated reaction temperature.

\section{EXPERIMENTAL SECTION}

General Information. The commercially available reagents were purchased from commercial sources, and they were used without further purification unless otherwise stated. The TADDOL derivatives $[(R, R)$-2, $(R, R)-S I-1,(R, R)-S I-3$, and $(R, R, R, R)-S I-4],{ }^{35,36}$ benzylphenylphosphine oxide $(\mathbf{1 j})$, methyl-phenylphosphine oxide $(\mathbf{1 k})$, butyl-phenylphosphine oxide (11), tert-butyl-phenylphosphine oxide $(\mathbf{1 m})$, and cyclohexyl-phenylphosphine oxide (1n) were synthesized as described in the literature, and their analytical data were identical to the ones reported in the literature. ${ }^{12 \mathrm{~b}, 24}$ The solvents were purchased from Merck Chemical Ltd., and they were used without further purification. Solvents used in moisture sensitive reactions were purified and dried according to the standard procedures. ${ }^{37}$ Dry solvents were stored over molecular sieves of 3 or $4 \AA$. The ${ }^{31} \mathrm{P},{ }^{19} \mathrm{~F}$, ${ }^{13} \mathrm{C}$, and ${ }^{1} \mathrm{H}$ NMR spectra were taken on a Bruker AV-300 or DRX500 spectrometer operating at $121.5,282.4,75.5$, and $300 \mathrm{MHz}$ or $202.5,470.6,125.8$, and $500 \mathrm{MHz}$, respectively. Chemical shifts $(\delta)$ are given in parts per million (ppm). Chemical shifts $(\delta)$ were for ${ }^{1} \mathrm{H}$ and ${ }^{13} \mathrm{C}$ in $\mathrm{CDCl}_{3}$ and referenced to 7.26 and $77.16 \mathrm{ppm}$, respectively. An $85 \%$ solution of $\mathrm{H}_{3} \mathrm{PO}_{4}$ was the external reference for ${ }^{31} \mathrm{P}$ NMR chemical shifts. Coupling constants are expressed in Hertz $(\mathrm{Hz})$. The following abbreviations are used: $\mathrm{s}=$ singlet, $\mathrm{d}=$ doublet, $\mathrm{t}=$ triplet, $\mathrm{q}$ $=$ quadruplet, $\mathrm{m}=$ multiplet, and $\mathrm{dd}=$ doublet of doublets. The exact mass measurements were performed using an Agilent $6230 \mathrm{C}$ TOF LCMS System with Agilent Jet Stream source in positive ESI mode (buffer: ammonium-formate in water/acetonitrile; drying gas: $325^{\circ} \mathrm{C}$; capillary: $3000 \mathrm{~V}$; Fragmentor $100 \mathrm{~V}$ ). LCMS measurements were performed using an Agilent 1100 and Agilent 6130 LCMS system in positive and negative electrospray mode. For the single crystal 
structure determination, the intensity data were collected on a Rigaku RAXIS-RAPID II diffractometer (using a graphite monochromator; Mo $\mathrm{K} \alpha$ radiation, $\lambda=0.71075 \AA$ ). The crystals were measured with fiber. Crystal Clear (developed by Rigaku Company) software was used for data collection and refinement. ${ }^{38}$ Numerical and empirical absorption corrections were applied to the data. ${ }^{39}$ The structures were solved by direct methods. Anisotropic full-matrix least-squares refinements were performed on F2 for all non-hydrogen atoms. Hydrogen atoms bonded to $\mathrm{C}$ atoms were placed in calculated positions and refined in a riding-model approximation. The computer programs used for the structure solution, refinement, and analysis of the structures were Shelx ${ }^{40}$ Sir2014, ${ }^{41}$ Wingx,${ }^{42}$ Platon, ${ }^{43}$ and Crystal Explorer. ${ }^{44}$ Melting points were obtained on a melting point apparatus and are uncorrected. The preparation of the air and moisture sensitive intermediates (6 and 7) or racemic secondary phosphine oxides $(\mathbf{1} \mathbf{a}-\mathbf{n})$ was carried out under a nitrogen atmosphere in Schlenk-type reaction vessels using standard Schlenk techniques. ${ }^{45}$ Thin layer chromatography (TLC) was performed on Merck precoated Silica gel $60 \mathrm{~F}_{254}$ or neutral $\mathrm{Al}_{2} \mathrm{O}_{3} 60 \mathrm{~F}_{254}$ aluminum plates with realization by UV irradiation, iodine, and phosphomolybdic acid. Column chromatography was performed on Silica gel 60 or neutral $\mathrm{Al}_{2} \mathrm{O}_{3} 90$ with a particle size of $0.063-0.200 \mathrm{~mm}$ supplied by Merck. Flash column chromatography was performed using a CombiFlash (Teledyne ISCO) with gradient elution on Silica gel 60 or neutral $\mathrm{Al}_{2} \mathrm{O}_{3} 90$ columns. The enantiomeric excess (ee) value of $3 \mathrm{e}$ was determined by ${ }^{31} \mathrm{P}$ NMR using $5.0 \mathrm{mg}(20 \mu \mathrm{mol})$ of the analyte, $4.8 \mu \mathrm{L}(30 \mu \mathrm{mol})$ of $(S)$-naphthyl-ethyl-amine as CSA, and $750 \mu \mathrm{L}$ of $\mathrm{CDCl}_{3}$ as solvent. Enantiomeric excess (ee) values of secondary and tertiary phosphine oxides $\mathbf{1} \mathbf{a}-\mathbf{n}, \mathbf{3} \mathbf{a}-\mathbf{d}$, and $\mathbf{3} \mathbf{f}-\mathbf{g}$ were determined by chiral HPLC on a PerkinElmer Series 200 instrument equipped with Phenomenex Lux $5 \mu \mathrm{m}$ Cellulose-1, Phenomenex Lux $5 \mu \mathrm{m}$ Cellulose-2, Phenomenex Lux $5 \mu \mathrm{m}$ Amylose-2 column, or Kromasil 5-Amycoat $(250 \times 4.6 \mathrm{~mm} \mathrm{ID}$, a mixture of hexane/ethanol was used as the eluent with a flow rate of $0.8 \mathrm{~mL} / \mathrm{min}\left(T=20^{\circ} \mathrm{C}\right.$, UV detector $\alpha=254 \mathrm{~nm}$ ). Exact chromatographic parameters are detailed in Table S7. Optical rotations were determined on a Perkin-Elmer 341 polarimeter.

Preparation of Racemic Diaryl Secondary Phosphine Oxides (1a-i). N,N-Diethylamino-chloro-phenylphosphine (6). Under nitrogen atmosphere, $21 \mathrm{~mL}(260 \mathrm{mmol})$ of anhydrous pyridine was added dropwise over $5 \mathrm{~min}$ to a solution of $17 \mathrm{~mL}$ (130 mmol) of $P, P$-dichlorophenylphosphine (4) in $100 \mathrm{~mL}$ of anhydrous hexane, and then, the opaque solution was stirred for $10 \mathrm{~min}$ at $25^{\circ} \mathrm{C}$. To this reaction mixture, $27 \mathrm{~mL}(260 \mathrm{mmol})$ of anhydrous diethylamine (5) was added dropwise over $20 \mathrm{~min}$. The resulting white suspension was refluxed in an oil bath for $3 \mathrm{~h}$, and it was cooled to 25 ${ }^{\circ} \mathrm{C}$. The precipitated salt was filtered through a sintered glass funnel under nitrogen atmosphere, and it was washed $2 \times$ with $50 \mathrm{~mL}$ of anhydrous hexane. The filtrate was concentrated on the rotary evaporator. Distillation under reduced pressure yielded $24 \mathrm{~g}(84 \%)$ of $\mathrm{N}, \mathrm{N}$-diethylamino-chloro-phenylphosphine (6) as colorless oil. bp: 95 ${ }^{\circ} \mathrm{C} @ 0.5$ mbar; (lit. bp: $68-70{ }^{\circ} \mathrm{C} @ 0.13$ mbar). ${ }^{46}$ The distillate was used immediately.

(2-Methylphenyl)-phenylphosphine oxide (1a) (Representative Procedure I). Under nitrogen atmosphere, a solution of $4.3 \mathrm{~g}(20$ mmol) $\mathrm{N}, \mathrm{N}$-diethylamino-chloro-phenylphosphine (6) in $10 \mathrm{~mL}$ of anhydrous THF was added dropwise over $1 \mathrm{~h}$ to a solution of 20 mmol of 2-methylphenyllithium at $-78{ }^{\circ} \mathrm{C}$ [2-methylphenyllithium was prepared by adding $13 \mathrm{~mL}(20 \mathrm{mmol})$ of $n$-butyllithium $(1.6 \mathrm{M}$ hexane solution) to a solution of $2.4 \mathrm{~mL}(20 \mathrm{mmol})$ of 2 bromotoluene and $24 \mathrm{~mL}$ of anhydrous THF over $30 \mathrm{~min}$ at -78 ${ }^{\circ} \mathrm{C}$ followed by an additional $30 \mathrm{~min}$ of stirring at the same temperature]. The reaction mixture was stirred for $2 \mathrm{~h}$ at $-78{ }^{\circ} \mathrm{C}$. Then, it was allowed to warm to $25^{\circ} \mathrm{C}$, and it was stirred overnight. The solution was concentrated under vacuum, and the residue was redissolved in $20 \mathrm{~mL}$ of toluene. Fifteen $\mathrm{mL}$ of $\mathrm{cc}$. $\mathrm{HCl}$ solution was added over $10 \mathrm{~min}$ at $0{ }^{\circ} \mathrm{C}$, and the resulting emulsion was stirred for $15 \mathrm{~min}$. Then, the $\mathrm{pH}$ was adjusted to 8 by adding $20 \%$ aqueous $\mathrm{NaOH}$ solution. The phases were separated, and the aqueous layer was extracted with DCM $(3 \times 40 \mathrm{~mL})$. The organic layers were combined, dried $\left(\mathrm{Na}_{2} \mathrm{SO}_{4}\right)$, and evaporated. The crude product was purified by flash column chromatography $\left(\mathrm{Al}_{2} \mathrm{O}_{3}\right.$, gradient elution, hexane to EtOAc) to give $4.0 \mathrm{~g}$ (92\%) of (2-methylphenyl)phenylphosphine oxide (1a) as a white solid. mp: $115-117{ }^{\circ} \mathrm{C}$ $\left(\mathrm{mp}_{\mathrm{lit}}: 121.5-123^{\circ} \mathrm{C}\right) ;{ }^{9 \mathrm{~b}}{ }^{31} \mathrm{P}\left\{{ }^{1} \mathrm{H}\right\} \operatorname{NMR}\left(121.5, \mathrm{MHz} \mathrm{CDCl}_{3}\right) \delta 21.9$ $\left(\delta_{\text {lit }} 21.9\right) ;{ }^{9 \mathrm{~b}}{ }^{1} \mathrm{H}$ NMR $\left(500 \mathrm{MHz}, \mathrm{CDCl}_{3}\right) \delta 8.09(\mathrm{~d}, 1 \mathrm{H}, J=480.1)$, $7.71-7.60(\mathrm{~m}, 3 \mathrm{H}), 7.53-7.50(\mathrm{~m}, 1 \mathrm{H}), 7.46-7.43(\mathrm{~m}, 3 \mathrm{H}), 7.33-$ $7.30(\mathrm{~m}, 1 \mathrm{H}), 7.23-7.20(\mathrm{~m}, 1 \mathrm{H}), 2.35(\mathrm{bs}, 3 \mathrm{H}) ;{ }^{13} \mathrm{C}\left\{{ }^{1} \mathrm{H}\right\}$ NMR $\left(125.8 \mathrm{MHz}, \mathrm{CDCl}_{3}\right) \delta 141.5(\mathrm{~d}, J=9.2), 132.8(\mathrm{~d}, J=2.6), 132.3(\mathrm{~d}$, $J=3.0), 132.3$ (d, $J=13.6), 131.5(\mathrm{~d}, J=100.4), 131.4(\mathrm{~d}, J=10.4)$, 130.8 (d, $J=11.4), 129.6$ (d, $J=101.0), 128.9$ (d, $J=12.7), 126.0$ (d, $J=13.6), 20.2\left(\mathrm{~d}, J=6.8\right.$ ); HRMS (ESI/TOF) $\mathrm{m} / z:[\mathrm{M}+\mathrm{H}]^{+}$Calcd for $\mathrm{C}_{13} \mathrm{H}_{14} \mathrm{OP}$ 217.0782; Found 217.0786.

(3-Methylphenyl)-phenylphosphine oxide (1b). The (3-methylphenyl)-phenylphosphine oxide (1b) was prepared according to Representative Procedure I by reacting $4.3 \mathrm{~g}(20 \mathrm{mmol})$ of $\mathrm{N}, \mathrm{N}$ diethylamino-chloro-phenylphosphine (6) in $10 \mathrm{~mL}$ of anhydrous THF with $20 \mathrm{mmol}$ of 3 -methylphenyllithium at $-78{ }^{\circ} \mathrm{C}$. 3Methylphenyllithium was prepared from $2.4 \mathrm{~mL}(20 \mathrm{mmol})$ of 3bromotoluene and $13 \mathrm{~mL}(20 \mathrm{mmol})$ of $n$-butyllithium ( $1.6 \mathrm{M}$ hexane solution) in $24 \mathrm{~mL}$ of anhydrous THF at $-78^{\circ} \mathrm{C}$. The crude product was purified by flash column chromatography $\left(\mathrm{Al}_{2} \mathrm{O}_{3}\right.$, gradient elution, hexane to EtOAc) to give $3.0 \mathrm{~g}(70 \%)$ of (3-methylphenyl)phenylphosphine oxide (1b) as a clear oil. ${ }^{31} \mathrm{P}\left\{{ }^{1} \mathrm{H}\right\}$ NMR $(121.5$ $\left.\mathrm{MHz}, \mathrm{CDCl}_{3}\right) \delta 21.8 ;{ }^{1} \mathrm{H} \mathrm{NMR}\left(500 \mathrm{MHz}, \mathrm{CDCl}_{3}\right) \delta 8.04(\mathrm{~d}, 1 \mathrm{H}, J=$ 479.6), 7.72-7.67 (m, 2H), 7.58-7.44 (m, 5H), 7.38-7.36 (m, 2H), $2.38(\mathrm{~s}, 3 \mathrm{H}) ;{ }^{13} \mathrm{C}\left\{{ }^{1} \mathrm{H}\right\}$ NMR $\left(75.5 \mathrm{MHz}, \mathrm{CDCl}_{3}\right) \delta 139.0(\mathrm{~d}, J=$ 12.7), 133.5 (d, $J=2.9$ ), 132.6 (d, $J=3.0), 131.8$ (d, $J=101.1), 131.3$ $(\mathrm{d}, J=11.1), 130.8(\mathrm{~d}, J=11.4), 130.0(\mathrm{~d}, J=100.8), 129.0$ (d, $J=$ 12.8), 128.9 (d, $J=13.7), 127.8(\mathrm{~d}, J=11.8), 21.5$; HRMS (ESI/ TOF) $m / z:[\mathrm{M}+\mathrm{H}]^{+}$Calcd for $\mathrm{C}_{13} \mathrm{H}_{14} \mathrm{OP}$ 217.0782; Found 217.0786.

(4-Methylphenyl)-phenylphosphine oxide (1c). The (4-methylphenyl)-phenylphosphine oxide (1c) was prepared according to Representative Procedure I by reacting $4.3 \mathrm{~g}(20 \mathrm{mmol})$ of $\mathrm{N}, \mathrm{N}$ diethylamino-chloro-phenylphosphine (6) in $10 \mathrm{~mL}$ of anhydrous THF with $20 \mathrm{mmol}$ of 4 -methylphenyllithium at $-78{ }^{\circ} \mathrm{C}$. The $4-$ methylphenyllithium was prepared from $2.5 \mathrm{~mL}(20 \mathrm{mmol})$ of 4 bromotoluene and $13 \mathrm{~mL}(20 \mathrm{mmol})$ of $n$-butyllithium ( $1.6 \mathrm{M}$ hexane solution) in $24 \mathrm{~mL}$ of anhydrous THF at $-78^{\circ} \mathrm{C}$. The crude product was purified by flash column chromatography $\left(\mathrm{Al}_{2} \mathrm{O}_{3}\right.$, gradient elution, hexane to EtOAc) to give $2.9 \mathrm{~g}(68 \%)$ of (4-methylphenyl)phenylphosphine oxide (1c) as white solid. mp: $70-72{ }^{\circ} \mathrm{C} ;{ }^{31} \mathrm{P}\left\{{ }^{1} \mathrm{H}\right\}$ $\operatorname{NMR}\left(121.5 \mathrm{MHz}, \mathrm{CDCl}_{3}\right) \delta 21.6\left(\delta_{\text {lit }} 21.9\right) ;{ }^{47}{ }^{1} \mathrm{H}$ NMR $(500 \mathrm{MHz}$, $\left.\mathrm{CDCl}_{3}\right) \delta 8.04(\mathrm{~d}, 1 \mathrm{H}, J=479.5), 7.71-7.66(\mathrm{~m}, 2 \mathrm{H}), 7.61-7.46(\mathrm{~m}$, 5H), 7.31-7.29 (m, 2H), $2.40(\mathrm{~s}, 3 \mathrm{H}) ;{ }^{13} \mathrm{C}\left\{{ }^{1} \mathrm{H}\right\}$ NMR $(75.5 \mathrm{MHz}$, $\left.\mathrm{CDCl}_{3}\right) \delta 143.4(\mathrm{~d}, J=2.6), 132.6(\mathrm{~d}, J=3.0), 131.9(\mathrm{~d}, J=101.7)$, 130.9 (d, $J=11.9), 130.9$ (d, $J=96.5), 130.8$ (d, $J=11.4), 129.8$ (d, $J$ $=13.3), 129.0(\mathrm{~d}, J=12.8), 21.8$; HRMS (ESI/TOF) $m / z:[\mathrm{M}+\mathrm{H}]^{+}$ Calcd for $\mathrm{C}_{13} \mathrm{H}_{14} \mathrm{OP}$ 217.0782; Found 217.0782.

(2-Trifluoromethylphenyl)-phenylphosphine oxide (1d). The (2trifluoromethylphenyl)-phenylphosphine oxide (1d) was prepared according to the Representative Procedure I by reacting $5.2 \mathrm{~g}(24$ $\mathrm{mmol}$ ) of $\mathrm{N}, \mathrm{N}$-diethylamino-chloro-phenylphosphine (6) in $12 \mathrm{~mL}$ of anhydrous THF with $24 \mathrm{mmol}$ of 2-trifluoromethylphenyllithium at $-78{ }^{\circ} \mathrm{C}$. The 2-trifluoromethylphenyllithium was prepared from 3.3 $\mathrm{mL}(24 \mathrm{mmol})$ of 2-bromobenzotrifluoride and $15 \mathrm{~mL}(24 \mathrm{mmol})$ of $n$-butyllithium (1.6 M hexane solution) in $28 \mathrm{~mL}$ of anhydrous THF at $-78{ }^{\circ} \mathrm{C}$. The crude product was purified by flash column chromatography $\left(\mathrm{Al}_{2} \mathrm{O}_{3}\right.$, gradient elution, hexane to EtOAc) to give $3.8 \mathrm{~g}$ (59\%) of (2-trifluoromethylphenyl)-phenylphosphine oxide (1d) as white solid. mp: $45{ }^{\circ} \mathrm{C} ;{ }^{31} \mathrm{P}\left\{{ }^{1} \mathrm{H}\right\}$ NMR $\left(121.5 \mathrm{MHz}, \mathrm{CDCl}_{3}\right)$ $\delta 15.4(\mathrm{q}, J=7.5) ;{ }^{1} \mathrm{H}$ NMR $\left(500 \mathrm{MHz}, \mathrm{CDCl}_{3}\right) \delta 8.33(\mathrm{dq}, 1 \mathrm{H}, J=$ 510.4, 3.1), 8.21-8.17 (m, 1H), 7.80-7.78 (m, 1H), 7.76-7.69 (m, $2 \mathrm{H}), 7.68-7.61(\mathrm{~m}, 2 \mathrm{H}), 7.57-7.53(\mathrm{~m}, 1 \mathrm{H}), 7.49-7.45(\mathrm{~m}, 2 \mathrm{H})$; ${ }^{13} \mathrm{C}\left\{{ }^{1} \mathrm{H}\right\} \operatorname{NMR}\left(75.5 \mathrm{MHz}, \mathrm{CDCl}_{3}\right) \delta 134.2(\mathrm{~d}, J=6.9), 132.8(\mathrm{~d}, J=$ 3.0), $132.6(\mathrm{~d}, J=2.5), 132.3$ (d, $J=10.7), 131.5(\mathrm{~d}, J=105.0), 131.4$ (dd, $J=39.1,6.4), 130.8$ (d, $J=11.7), 130.6$ (d, $J=101.4), 129.0$ (d, $J$ = 13.2), $126.8(\mathrm{~m}), 123.8(\mathrm{dd}, J=274.3,2.6) ;{ }^{19} \mathrm{~F}$ NMR $(282.4 \mathrm{MHz}$, 
$\left.\mathrm{CDCl}_{3}\right) \delta-56.9\left(\mathrm{~d}, J=7.4\right.$ ); HRMS (ESI/TOF) $m / z:[\mathrm{M}+\mathrm{H}]^{+}$ Calcd for $\mathrm{C}_{13} \mathrm{H}_{11} \mathrm{~F}_{3} \mathrm{OP}$ 271.0500; Found 271.0499.

(3-Trifluoromethylphenyl)-phenylphosphine oxide (1e). (3-Trifluoromethylphenyl)-phenylphosphine oxide (1e) was prepared according to Representative Procedure I by reacting $5.2 \mathrm{~g}$ (24 $\mathrm{mmol}$ ) of $\mathrm{N}, \mathrm{N}$-diethylamino-chloro-phenylphosphine (6) in $12 \mathrm{~mL}$ of anhydrous THF with $24 \mathrm{mmol}$ of 3-trifluoromethylphenyllithium at $-78{ }^{\circ} \mathrm{C}$. 3-Trifluoromethylphenyllithium was prepared from $3.3 \mathrm{~mL}$ (24 mmol) of 3-bromobenzotrifluoride and $15 \mathrm{~mL}(24 \mathrm{mmol})$ of $n$ butyllithium (1.6 M hexane solution) in $28 \mathrm{~mL}$ of anhydrous THF at $-78{ }^{\circ} \mathrm{C}$. The crude product was purified by flash column chromatography $\left(\mathrm{Al}_{2} \mathrm{O}_{3}\right.$, gradient elution, hexane to EtOAc) to give $3.2 \mathrm{~g}(50 \%)$ of (3-trifluoromethylphenyl)-phenylphosphine oxide (1e) as clear oil. ${ }^{31} \mathrm{P}\left\{{ }^{1} \mathrm{H}\right\}$ NMR $\left(121.5 \mathrm{MHz}, \mathrm{CDCl}_{3}\right) \delta 19.8 ;{ }^{1} \mathrm{H}$ NMR $\left(500 \mathrm{MHz}, \mathrm{CDCl}_{3}\right) \delta 8.12(\mathrm{~d}, 1 \mathrm{H}, J=486.2), 7.99(\mathrm{~d}, 1 \mathrm{H}, J=$ 13.5), 7.89-7.81 (m, 2H), 7.73-7.69 (m, 2H), 7.66-7.59 (m, $2 \mathrm{H})$, 7.55-7.51 (m, 2H); ${ }^{13} \mathrm{C}\left\{{ }^{1} \mathrm{H}\right\}$ NMR $\left(75.5 \mathrm{MHz}, \mathrm{CDCl}_{3}\right) \delta 134.1(\mathrm{~d}, J$ $=11.1), 133.2(\mathrm{~d}, J=3.0), 133.2(\mathrm{~d}, J=99.9), 131.7(\mathrm{dd}, J=32.1$, $13.6), 130.8(\mathrm{~d}, J=11.7), 130.6(\mathrm{~d}, J=102.9), 129.7(\mathrm{~d}, J=12.5)$, 129.4 (d, $J=6.2), 129.3$ (d, $J=13.1), 127.7(\mathrm{~m}), 123.6$ (dd, $J=272.8$, $\left.1.7) ;{ }^{19} \mathrm{~F} \mathrm{NMR} \mathrm{(282.4} \mathrm{MHz,} \mathrm{CDCl}_{3}\right) \delta-62.8$; HRMS (ESI/TOF) $m / z:[\mathrm{M}+\mathrm{H}]^{+}$Calcd for $\mathrm{C}_{13} \mathrm{H}_{11} \mathrm{~F}_{3} \mathrm{OP}$ 271.0500; Found 271.0500.

(4-Trifluoromethylphenyl)-phenylphosphine oxide (1f). (4-Trifluoromethylphenyl)-phenylphosphine oxide (1f) was prepared according to Representative Procedure I by reacting $5.2 \mathrm{~g}$ (24 $\mathrm{mmol}$ ) of $\mathrm{N}, \mathrm{N}$-diethylamino-chloro-phenylphosphine (6) in $12 \mathrm{~mL}$ of anhydrous THF with $24 \mathrm{mmol}$ of 4-trifluoromethylphenyllithium at $-78{ }^{\circ} \mathrm{C}$. 4-Trifluoromethylphenyllithium was prepared from $3.3 \mathrm{~mL}$ (24 mmol) of 4-bromobenzotrifluoride and $15 \mathrm{~mL}(24 \mathrm{mmol})$ of $n$ butyllithium (1.6 M hexane solution) in $28 \mathrm{~mL}$ of anhydrous THF at $-78{ }^{\circ} \mathrm{C}$. The crude product was purified by flash column chromatography $\left(\mathrm{Al}_{2} \mathrm{O}_{3}\right.$, gradient elution, hexane to EtOAc) to give $3.3 \mathrm{~g}$ (51\%) of (4-trifluoromethylphenyl)-phenylphosphine oxide (1f) as clear oil. ${ }^{31} \mathrm{P}\left\{{ }^{1} \mathrm{H}\right\} \operatorname{NMR}\left(121.5 \mathrm{MHz}, \mathrm{CDCl}_{3}\right) \delta 19.8\left(\delta_{\text {lit }} 19.6\right) ;{ }^{48}$ ${ }^{1} \mathrm{H}$ NMR (500 MHz, $\left.\mathrm{CDCl}_{3}\right) \delta 8.11(\mathrm{~d}, 1 \mathrm{H}, J=486.5), 7.87-7.81$ (m, 2H), 7.76-7.68 (m, 4H), 7.63-7.58 (m, 1H), 7.55-7.50 (m, $2 \mathrm{H}) ;{ }^{13} \mathrm{C}\left\{{ }^{1} \mathrm{H}\right\}$ NMR $\left(75.5 \mathrm{MHz}, \mathrm{CDCl}_{3}\right) \delta 135.8(\mathrm{~d}, J=97.9), 134.5$ (dd, $J=32.8,3.1), 133.2$ (d, $J=2.9), 131.4$ (d, $J=11.7), 130.8$ (d, $J=$ $11.7), 129.9$ (d, $J=$ not visible), 129.3 (d, $J=13.1), 125.9$ (dq, $J=$ $12.8,3.6), 123.6(\mathrm{dd}, J=272.9,1.0) ;{ }^{19} \mathrm{~F} \mathrm{NMR}\left(282.4 \mathrm{MHz}, \mathrm{CDCl}_{3}\right)$ $\delta$-63.2; HRMS (ESI/TOF) $m / z$ : $[\mathrm{M}+\mathrm{H}]^{+}$Calcd for $\mathrm{C}_{13} \mathrm{H}_{11} \mathrm{~F}_{3} \mathrm{OP}$ 271.0500; Found 271.0502.

(2-Methoxyphenyl)-phenylphosphine oxide (1g). (2-Methoxyphenyl)-phenylphosphine oxide (1g) was prepared according to Representative Procedure I by reacting $4.3 \mathrm{~g}(20 \mathrm{mmol})$ of $\mathrm{N}, \mathrm{N}$ diethylamino-chloro-phenylphosphine $(6)$ in $10 \mathrm{~mL}$ of anhydrous THF with $20 \mathrm{mmol}$ of 2-methoxyphenyllithium at $-78{ }^{\circ} \mathrm{C}$. 2Methoxyphenyllithium was prepared from $2.5 \mathrm{~mL}(20 \mathrm{mmol})$ of 2bromoanisole and $13 \mathrm{~mL}(20 \mathrm{mmol})$ of $n$-butyllithium ( $1.6 \mathrm{M}$ hexane solution) in $24 \mathrm{~mL}$ of anhydrous THF at $-78^{\circ} \mathrm{C}$. The crude product was purified by flash column chromatography $\left(\mathrm{Al}_{2} \mathrm{O}_{3}\right.$, gradient elution, hexane to EtOAc) to give $3.0 \mathrm{~g}(65 \%)$ of (2-methoxyphenyl)phenylphosphine oxide $(\mathbf{1 g})$ as pale yellow solid. mp: $94-96{ }^{\circ} \mathrm{C}$ $\left(\mathrm{mp}_{\text {lit }}: 101-103{ }^{\circ} \mathrm{C}\right) ;{ }^{49}{ }^{31} \mathrm{P}\left\{{ }^{1} \mathrm{H}\right\}$ NMR $\left(121.5 \mathrm{MHz}, \mathrm{CDCl}_{3}\right) \delta 12.5$ $\left(\delta_{\text {lit }} 14.4\right) ;{ }^{49} \mathrm{H} \mathrm{NMR}\left(500 \mathrm{MHz}, \mathrm{CDCl}_{3}\right) \delta 8.16(\mathrm{~d}, 1 \mathrm{H}, J=499.0)$, 7.81-7.70 (m, 3H), 7.55-7.43 (m, 4H), 7.11-7.08 (m, 1H), 6.92$6.89(\mathrm{~m}, 1 \mathrm{H}), 3.77(\mathrm{~s}, 3 \mathrm{H}) ;{ }^{13} \mathrm{C}\left\{{ }^{1} \mathrm{H}\right\} \operatorname{NMR}\left(75.5 \mathrm{MHz}, \mathrm{CDCl}_{3}\right) \delta$ $160.8(\mathrm{~d}, J=3.8), 134.5(\mathrm{~d}, J=1.9), 133.2(\mathrm{~d}, J=7.1), 132.3(\mathrm{~d}, J=$ 104.5), $132.1(\mathrm{~d}, J=3.0), 130.6(\mathrm{~d}, J=11.8), 128.6(\mathrm{~d}, J=13.1)$, $121.2(\mathrm{~d}, J=12.1), 119.6$ (d, $J=101.9), 110.9$ (d, $J=6.1)$, 55.6; HRMS (ESI/TOF) $m / z:[\mathrm{M}+\mathrm{H}]^{+}$Calcd for $\mathrm{C}_{13} \mathrm{H}_{14} \mathrm{O}_{2} \mathrm{P}$ 233.0731; Found 233.0733.

(2-Phenylphenyl)-phenylphosphine oxide (1h). (2-Phenylphenyl)-phenylphosphine oxide (1h) was prepared according to Representative Procedure I by reacting $4.3 \mathrm{~g}(20 \mathrm{mmol})$ of $\mathrm{N}, \mathrm{N}$ diethylamino-chloro-phenylphosphine $(6)$ in $10 \mathrm{~mL}$ of anhydrous THF with $20 \mathrm{mmol}$ of 2-phenylphenyllithium at $-78{ }^{\circ} \mathrm{C}$. 2Phenylphenyllithium was prepared from $3.4 \mathrm{~mL}(20 \mathrm{mmol})$ of 2 bromobiphenyl and $13 \mathrm{~mL}(20 \mathrm{mmol})$ of $n$-butyllithium $(1.6 \mathrm{M}$ hexane solution) in $24 \mathrm{~mL}$ of anhydrous THF at $-78{ }^{\circ} \mathrm{C}$. The crude product was purified by flash column chromatography $\left(\mathrm{Al}_{2} \mathrm{O}_{3}\right.$, gradient elution, hexane to EtOAc) to give $4.5 \mathrm{~g}$ (81\%) of (2phenylphenyl)-phenylphosphine oxide (1h) as clear oil. ${ }^{31} \mathrm{P}\left\{{ }^{1} \mathrm{H}\right\}$ NMR $\left(202.5 \mathrm{MHz}, \mathrm{CDCl}_{3}\right) \delta 18.4\left(\delta_{\text {lit }} 18.4\right) ;{ }^{10 \mathrm{~b}}{ }^{1} \mathrm{H}$ NMR $(500$ $\left.\mathrm{MHz}, \mathrm{CDCl}_{3}\right) \delta 7.95(\mathrm{dd}, 1 \mathrm{H}, J=14.1,7.6), 7.88(\mathrm{~d}, 1 \mathrm{H}, J=493.3)$, $7.60(\mathrm{t}, 1 \mathrm{H}, J=7.5), 7.51(\mathrm{t}, 1 \mathrm{H}, J=7.6), 7.43-7.21(\mathrm{~m}, 11 \mathrm{H})$; ${ }^{13} \mathrm{C}\left\{{ }^{1} \mathrm{H}\right\}$ NMR $\left(125.8 \mathrm{MHz}, \mathrm{CDCl}_{3}\right) \delta 146.1(\mathrm{~d}, J=10.1), 139.3(\mathrm{~d}, J$ $=5.2), 132.9$ (d, $J=10.4), 132.4(\mathrm{~d}, J=2.7), 132.0(\mathrm{~d}, J=2.9), 131.7$ $(\mathrm{d}, J=102.5), 130.8(\mathrm{~d}, J=9.3), 130.6(\mathrm{~d}, J=11.5), 130.4(\mathrm{~d}, J=$ $105.7), 129.5,128.5(\mathrm{~d}, J=13.1), 128.3,128.1,127.6(\mathrm{~d}, J=12.0)$; HRMS (ESI/TOF) $m / z:[\mathrm{M}+\mathrm{H}]^{+}$Calcd for $\mathrm{C}_{18} \mathrm{H}_{16} \mathrm{OP} 279.0939$; Found 279.0934.

(1-Naphthyl)-phenylphosphine oxide (1i). (1-Naphthyl)-phenylphosphine oxide (1i) was prepared according to Representative Procedure I by reacting $5.2 \mathrm{~g}(24 \mathrm{mmol})$ of $N, N$-diethylamino-chlorophenylphosphine (6) in $12 \mathrm{~mL}$ of anhydrous THF with $24 \mathrm{mmol}$ of 1 naphthyllithium at $-78{ }^{\circ} \mathrm{C}$. 1-Naphthyllithium was prepared from 3.4 $\mathrm{mL}(24 \mathrm{mmol})$ of 1-bromonaphthalene and $15 \mathrm{~mL}(24 \mathrm{mmol})$ of $n$ butyllithium (1.6 M hexane solution) in $28 \mathrm{~mL}$ of anhydrous THF at $-78{ }^{\circ} \mathrm{C}$. The crude product was purified by flash column chromatography $\left(\mathrm{Al}_{2} \mathrm{O}_{3}\right.$, gradient elution, hexane to EtOAc) to give $4.5 \mathrm{~g}(74 \%)$ of (1-naphthyl)-phenylphosphine oxide (1i) as clear oil. ${ }^{31} \mathrm{P}\left\{{ }^{1} \mathrm{H}\right\}$ NMR $\left(121.5 \mathrm{MHz}, \mathrm{CDCl}_{3}\right) \delta 23.2\left(\delta_{\text {lit }} 23.2\right) ;{ }^{9 \mathrm{~b}}{ }^{1} \mathrm{H}$ NMR $\left(500 \mathrm{MHz}, \mathrm{CDCl}_{3}\right) \delta 8.43(\mathrm{~d}, 1 \mathrm{H}, J=484.1), 8.28(\mathrm{~d}, 1 \mathrm{H}, J=8.13)$, $8.08(\mathrm{~d}, 1 \mathrm{H}, J=8.31), 8.00-7.90(\mathrm{~m}, 2 \mathrm{H}), 7.75-7.70(\mathrm{~m}, 2 \mathrm{H})$, 7.60-7.43 (m, 6H); ${ }^{13} \mathrm{C}\left\{{ }^{1} \mathrm{H}\right\}$ NMR $\left(75.5 \mathrm{MHz}, \mathrm{CDCl}_{3}\right) \delta 133.9(\mathrm{~d}, J$ $=3.0), 133.8$ (d, $J=9.0), 132.8$ (d, $J=8.7), 132.5$ (d, $J=3.0), 132.3$ (d, $J=13.4), 131.7(\mathrm{~d}, J=102.8), 130.9(\mathrm{~d}, J=11.4), 129.2(\mathrm{~d}, J=$ $1.6), 129.0(\mathrm{~d}, J=12.8), 127.9,127.6(\mathrm{~d}, J=100.3), 127.0,125.5$ (d, $J$ = 7.5), $124.9(\mathrm{~d}, J=15.4)$; HRMS (ESI/TOF) $m / z:[\mathrm{M}+\mathrm{H}]^{+}$Calcd for $\mathrm{C}_{16} \mathrm{H}_{14} \mathrm{OP}$ 253.0782; Found 253.0781.

Preparation of ((2R,3R)-1,4-Dioxaspiro[4.5]decane-2,3-diyl)bis(bis(4-(tert-butyl)phenyl)methanol) $[(R, R)-\mathrm{SI}-2]$. ( $(R, R)-\mathrm{SI}-2$ was synthesized according to a modified procedure of Beck et al. ${ }^{35}$ To a solution of $44 \mathrm{mmol}$ of (4-(tert-butyl)phenyl)magnesium bromide in $35 \mathrm{~mL}$ of anhydrous THF was added $2.5 \mathrm{~g}(8.7 \mathrm{mmol})$ of diethyl $(2 R, 3 R)$-1,4-dioxaspiro[4.5] decane-2,3-dicarboxylate in $15 \mathrm{~mL}$ of anhydrous THF over $30 \mathrm{~min}$ at $0{ }^{\circ} \mathrm{C}$ under nitrogen atmosphere. [(4-(tert-butyl)phenyl)magnesium bromide was prepared from 7.6 $\mathrm{mL}(44 \mathrm{mmol})$ of 1-bromo-4-(tert-butyl)benzene and $1.2 \mathrm{~g}$ (48 $\mathrm{mmol}$ ) of $\mathrm{Mg}$ in $35 \mathrm{~mL}$ of anhydrous THF]. The resulting solution was heated at reflux in an oil bath for $4 \mathrm{~h}$; then, it was allowed to cool to room temperature, and it was stirred overnight. $40 \mathrm{~mL}$ of saturated $\mathrm{NH}_{4} \mathrm{Cl}$ and $20 \mathrm{~mL}$ of water were added. The phases were separated, and the aqueous layer was extracted with DCM $(3 \times 40 \mathrm{~mL})$. The organic layers were combined, dried $\left(\mathrm{Na}_{2} \mathrm{SO}_{4}\right)$, and evaporated. The crude product was purified by flash column chromatography (silica gel, gradient elution, hexane to $\left.\mathrm{CHCl}_{3}\right)$ to give $4.3 \mathrm{~g}(67 \%)$ of $((2 R, 3 R)$-1,4-dioxaspiro[4.5] decane-2,3-diyl)bis(bis(4-(tert-butyl)phenyl)methanol) $[(R, R)-\mathrm{SI}-2]$ as a white solid. mp: $160-163{ }^{\circ} \mathrm{C}$; $[\alpha]_{\mathrm{D}}{ }^{25}=-60.9\left(c=1.00, \mathrm{CHCl}_{3}\right) ;{ }^{1} \mathrm{H}$ NMR $\left(500 \mathrm{MHz}, \mathrm{CDCl}_{3}\right) \delta$ $7.47-7.29(\mathrm{~m}, 16 \mathrm{H}), 4.59(\mathrm{~s}, 2 \mathrm{H}), 3.97(\mathrm{~s}, 2 \mathrm{H}), 1.46-1.03(\mathrm{~m}$, $46 \mathrm{H}) ;{ }^{13} \mathrm{C}\left\{{ }^{1} \mathrm{H}\right\}$ NMR $\left(125.8 \mathrm{MHz}, \mathrm{CDCl}_{3}\right) \delta 150.0,149.7,143.6$, 139.9, 128.1, 127.3, 124.9, 124.0, 109.9, 80.9, 77.9, 36.5, 34.4, 31.4, 31.3, 25.2, 24.1; HRMS (ESI/TOF) $\mathrm{m} / \mathrm{z}:[\mathrm{M}-\mathrm{H}]^{-}$Calcd for $\mathrm{C}_{50} \mathrm{H}_{65} \mathrm{O}_{4} \mathrm{P}$ 729.4888; Found 729.4885.

Representative Resolution Procedures. Over the course of this research project, it was observed that even the residual water content of the solvent may influence the outcome of the resolution in a negative manner. Thus, all the solvents used for resolution were dried according to the standard procedures. Dry solvents were stored over molecular sieves of 3 or $4 \AA$.

Resolution of (2-Methylphenyl)-phenylphosphine oxide (1a) with spiro-TADDOL $[(R, R)-2]$ Using the Crystallization Method (Representative Procedure II). $0.10 \mathrm{~g}(0.46 \mathrm{mmol})$ of racemic (2methylphenyl)-phenylphosphine oxide (1a) and $0.23 \mathrm{~g}(0.46 \mathrm{mmol})$ of spiro-TADDOL $[(R, R)-2]$ were dissolved in $1.4 \mathrm{~mL}$ of hot $2-\mathrm{PrOH}$ using a hot plate as the heat source. The colorless crystalline diastereomeric complex of $(S)$-1a.(spiro-TADDOL) $)_{2}$ appeared after cooling the mixture to $25{ }^{\circ} \mathrm{C}$. After standing at $25{ }^{\circ} \mathrm{C}$ for $3 \mathrm{~h}$, the 
crystals were separated by filtration and washed with $0.46 \mathrm{~mL}$ of 2 PrOH to give $0.25 \mathrm{~g}(89 \%)$ of $(S)-\mathbf{1 a} \cdot$ (spiro-TADDOL $)_{2}$ with a de of $79 \%$. The diastereomeric complex $(S)-1 \mathrm{a} \cdot(\text { spiro-TADDOL })_{2}$ was purified by two recrystallizations from $1.4 \mathrm{~mL}$ of $2-\mathrm{PrOH}$ according to the procedure described above to afford $0.18 \mathrm{~g}(65 \%)$ of the $(S)-1 \mathrm{a}$. (spiro-TADDOL) $)_{2}$ with a de of $98 \%$ (Scheme 2; Table S2, Entry 1). $(S)$-(2-Methylphenyl)-phenylphosphine oxide $[(S)$-1a] was recovered from the diastereomer by flash column chromatography (silica gel, gradient elution, DCM to DCM-MeOH 95:5) to give $0.031 \mathrm{~g}(61 \%)$ of $(S)$-(2-methylphenyl)-phenylphosphine oxide $[(S)$-1a] with an ee of $98 \%$.

The resolution of secondary phosphine oxides (1) with TADDOL derivatives was performed according to Representative Procedure II when $i-\mathrm{Pr}_{2} \mathrm{O}$, acetone, $\mathrm{MeOH}, \mathrm{EtOH}$, or $2-\mathrm{PrOH}$ was used as solvent. All conditions and results can be found in Tables S1, S2, and S4. Scheme 2 shows the selected results.

Resolution of (2-Methylphenyl)-phenylphosphine oxide (1a) with spiro-TADDOL $[(R, R)-2]$ Using the Precipitation Method (Representative Procedure III). $0.10 \mathrm{~g}(0.46 \mathrm{mmol})$ of racemic (2methylphenyl)-phenylphosphine oxide (1a) and $0.12 \mathrm{~g}(0.23 \mathrm{mmol})$ of spiro-TADDOL $[(R, R)-2]$ were dissolved in $0.58 \mathrm{~mL}$ of hot toluene using a hot plate as the heat source, and then, $0.58 \mathrm{~mL}$ of hexane was added. The colorless crystalline diastereomeric complex of (S)-1a.(spiro-TADDOL) appeared immediately. After standing at 25 ${ }^{\circ} \mathrm{C}$ for $3 \mathrm{~h}$, the crystals were separated by filtration and washed with $0.20 \mathrm{~mL}$ of hexane to give $0.13 \mathrm{~g}(75 \%)$ of $(S)-1 \mathrm{a} \cdot($ spiro-TADDOL) with a de of $77 \%$. The diastereomeric complex (S)-1a.(spiroTADDOL) was purified by two recrystallizations from a mixture of $0.58 \mathrm{~mL}$ of toluene and $0.58 \mathrm{~mL}$ of hexane according to the procedure described above to afford $0.093 \mathrm{~g}(55 \%)$ of the $(S)$-1 a.(spiroTADDOL) with a de of 95\% (Scheme 2; Table S3, Entry 1). (S)-(2Methylphenyl)-phenylphosphine oxide [(S)-1a] was recovered from the diastereomer by flash column chromatography (silica gel, gradient elution, DCM to DCM-MeOH 95:5) to give $0.025 \mathrm{~g}(50 \%)$ of $(S)$ (2-methylphenyl)-phenylphosphine oxide [(S)-1a] with an ee of $95 \%$.

The resolution of secondary phosphine oxides (1) with TADDOL derivatives was performed according to Representative Procedure III when a toluene/hexane or EtOAc/hexane mixture was used as solvent. All conditions and results can be found in Tables S1, S3, and S4. Scheme 2 shows the selected results.

(S)-(2-Methylphenyl)-phenylphosphine Oxide $[(S)-1 a] .[\alpha]_{\mathrm{D}}{ }^{25}=$ -44.2 ( $c=1.07, \mathrm{CHCl}_{3}$, ee = 98\%), Chiral HPLC: Phenomenex Lux $5 \mu \mathrm{m}$ Amylose-2 column, hexane/ethanol (85:15), $t_{\mathrm{R} 1} 20.8 \min (R)$, $t_{\mathrm{R} 2} 22.5 \mathrm{~min}(S)$.

(-)-(3-Methylphenyl)-phenylphosphine Oxide $[(-)-1 \boldsymbol{b}] .[\alpha]_{\mathrm{D}}{ }^{25}=$ $-1.3\left(c=1.35, \mathrm{CHCl}_{3}\right.$, ee $\left.=62 \%\right)$, Chiral HPLC: Phenomenex Lux 5 $\mu \mathrm{m}$ Cellulose-2 column, hexane/ethanol (50:50), $t_{\mathrm{R} 1} 11.1 \mathrm{~min}(-)$, $t_{\mathrm{R} 2} 12.8 \min (+)$.

(-)-(4-Methylphenyl)-phenylphosphine Oxide $[(-)-1 c] .[\alpha]_{\mathrm{D}}{ }^{25}=$ $-7.2\left(c=0.72, \mathrm{CHCl}_{3}\right.$, ee $\left.=99 \%\right)$, Chiral HPLC: Phenomenex Lux 5 $\mu \mathrm{m}$ Amylose-2 column, hexane/ethanol (50:50), $t_{\mathrm{R} 1} 10.3 \mathrm{~min}(-), t_{\mathrm{R} 2}$ $11.2 \min (+)$.

(2-Trifuoromethylphenyl)-phenylphosphine Oxide (1d). $[\alpha]_{\mathrm{D}}^{25}=$ not measured, ee $=0 \%$, Chiral HPLC: Phenomenex Lux $5 \mu \mathrm{m}$ Cellulose-2 column, hexane/ethanol (50:50), $t_{\mathrm{R} 1} 7.3 \mathrm{~min}, t_{\mathrm{R} 2} 7.9 \mathrm{~min}$.

(+)-(3-Trifuoromethylphenyl)-phenylphosphine Oxide [(+)-1e]. $[\alpha]_{\mathrm{D}}{ }^{25}=+10.0\left(c=0.78, \mathrm{CHCl}_{3}\right.$, ee $\left.=79 \%\right)$; Chiral HPLC: Phenomenex Lux $5 \mu \mathrm{m}$ Amylose-2 column, hexane/ethanol (50:50), $t_{\mathrm{R} 1} 6.7 \mathrm{~min}(+), t_{\mathrm{R} 2} 8.7 \mathrm{~min}(-)$.

(+)-(4-Trifuoromethylphenyl)-phenylphosphine Oxide [(+)-1f]. $[\alpha]_{\mathrm{D}}{ }^{25}=+13.0\left(c=0.68, \mathrm{CHCl}_{3}\right.$, ee $\left.=99 \%\right)$; Chiral HPLC: Phenomenex Lux $5 \mu \mathrm{m}$ Amylose-2 column, hexane/ethanol (50:50), $t_{\mathrm{R} 1} 6.4 \min (+), t_{\mathrm{R} 2} 8.3 \min (-)$.

(R)-(2-Methoxylphenyl)-phenylphosphine Oxide $[(R)-1 g] .[\alpha]_{\mathrm{D}}{ }^{25}$ $=+40.9\left(c=0.91, \mathrm{CHCl}_{3}\right.$, ee $\left.=67 \%\right)$, Chiral HPLC: Phenomenex Lux $5 \mu \mathrm{m}$ Cellulose-1 column, hexane/ethanol (85:15), $t_{\mathrm{R} 1} 10.8 \mathrm{~min}$ $(S), t_{\mathrm{R} 2} 15.4 \min (R)$.

(S)-(2-Phenylphenyl)-phenylphosphine Oxide $[(S)-1 \boldsymbol{h}] \cdot[\alpha]_{\mathrm{D}}{ }^{25}=$ $-30.4\left(c=0.58, \mathrm{CHCl}_{3}\right.$, ee $\left.=40 \%\right)$; Chiral HPLC: Phenomenex Lux
$5 \mu \mathrm{m}$ Cellulose-2 column, hexane/ethanol (50:50), $t_{\mathrm{R} 1} 10.0 \mathrm{~min}(R)$, $t_{\mathrm{R} 2} 12.0 \mathrm{~min}(S)$.

(R)-(1-Naphthyl)-phenylphosphine Oxide $[(R)-1 i] .[\alpha]_{\mathrm{D}}{ }^{25}=-9.7$ $\left(c=1.79, \mathrm{CHCl}_{3}\right.$, ee $\left.=83 \%\right)$; Chiral HPLC: Phenomenex Lux $5 \mu \mathrm{m}$ Amylose-2 column, hexane/ethanol (50:50), $t_{\mathrm{R} 1} 8.9 \mathrm{~min}(R), t_{\mathrm{R} 2} 9.8$ $\min (S)$.

(S)-Benzyl-phenylphosphine Oxide $[(S)-1 j] .[\alpha]_{\mathrm{D}}{ }^{25}=+47.8(c=$ $0.49, \mathrm{CHCl}_{3}$, ee $\left.=87 \%\right)$; Chiral HPLC: Phenomenex Lux $5 \mu \mathrm{m}$ Amylose-2 column, hexane/ethanol (50:50), $t_{\mathrm{R} 1} 9.7 \mathrm{~min}(S), t_{\mathrm{R} 2} 16.1$ $\min (R) ;{ }^{31} \mathrm{P}\left\{{ }^{1} \mathrm{H}\right\}$ NMR $\left(202.5 \mathrm{MHz}, \mathrm{CDCl}_{3}\right) \delta 29.5\left(\delta_{\text {lit }} 29.6\right) ;{ }^{9 \mathrm{~b}}{ }^{1} \mathrm{H}$ NMR (500 MHz, $\left.\mathrm{CDCl}_{3}\right) \delta 7.56-7.41(\mathrm{~m}, 5 \mathrm{H}), 7.47(\mathrm{dt}, J=474.7$, 3.6, $1 \mathrm{H}), 7.27-7.22(\mathrm{~m}, 3 \mathrm{H}), 7.06-7.04(\mathrm{~m}, 2 \mathrm{H}), 3.48$ (ddd, $J=$ $17.3,14.5,3.0,1 \mathrm{H}), 3.35(\mathrm{td}, J=14.9,4.2,1 \mathrm{H}) ;{ }^{13} \mathrm{C}\left\{{ }^{1} \mathrm{H}\right\} \mathrm{NMR}$ $\left(125.8 \mathrm{MHz}, \mathrm{CDCl}_{3}\right) \delta 132.7$ (d, $\left.J=3.0\right), 130.6(\mathrm{~d}, J=7.4), 130.2(\mathrm{~d}$, $J=10.8), 130.1(\mathrm{~d}, J=97.0), 129.9(\mathrm{~d}, J=5.7), 129.0(\mathrm{~d}, J=3.1)$, 128.8 (d, $J=12.4$ ), 127.4 (d, $J=3.6$ ), 38.9 (d, $J=62.6$ ); HRMS (ESI/TOF) $\mathrm{m} / z$ : $[\mathrm{M}+\mathrm{H}]^{+}$Calcd for $\mathrm{C}_{13} \mathrm{H}_{14} \mathrm{OP}$ 217.0782; Found 217.0778.

(R)-Methyl-phenylphosphine Oxide $[(R)-1 k] .[\alpha]_{\mathrm{D}}{ }^{25}=+11.4(c=$ $0.70, \mathrm{CHCl}_{3}$, ee $\left.=99 \%\right)$; Chiral HPLC: Phenomenex Lux $5 \mu \mathrm{m}$ Cellulose-2 column, hexane/ethanol (50:50), $t_{\mathrm{R} 1} 9.1 \min (S), t_{\mathrm{R} 2} 10.8$ $\min (R) ;{ }^{31} \mathrm{P}\left\{{ }^{1} \mathrm{H}\right\}$ NMR $\left(202.5 \mathrm{MHz}, \mathrm{CDCl}_{3}\right) \delta 20.4\left(\delta_{\text {lit }} 20.3\right) ;{ }^{9 \mathrm{~b}} \mathrm{H}$ NMR $\left(500 \mathrm{MHz}, \mathrm{CDCl}_{3}\right) \delta 7.69-7.64(\mathrm{~m}, 2 \mathrm{H}), 7.59(\mathrm{dq}, J=472.4$, $3.8,1 \mathrm{H}), 7.54-7.44(\mathrm{~m}, 3 \mathrm{H}), 1.75(\mathrm{dd}, J=14.0,3.8 \mathrm{~Hz}, 3 \mathrm{H})$; ${ }^{13} \mathrm{C}\left\{{ }^{1} \mathrm{H}\right\}$ NMR (125.8 MHz, $\left.\mathrm{CDCl}_{3}\right) \delta 132.5(\mathrm{~d}, J=2.9), 132.0(\mathrm{~d}, J$ = 99.9), 129.6 (d, $J=11.3$ ), 129.0 (d, $J=12.7), 16.3$ (d, $J=69.0$ ); HRMS (ESI/TOF) $\mathrm{m} / \mathrm{z}$ : $[\mathrm{M}+\mathrm{H}]^{+}$Calcd for $\mathrm{C}_{7} \mathrm{H}_{10} \mathrm{OP}$ 141.0469; Found 141.0464 .

(S)-Butyl-phenylphosphine Oxide $[(S)-11] \cdot[\alpha]_{\mathrm{D}}{ }^{25}=-11.2(c=$ $0.51, \mathrm{CHCl}_{3}$, ee $\left.=45 \%\right)$; Chiral HPLC: Phenomenex Lux $5 \mu \mathrm{m}$ Amylose-2 column, hexane/ethanol (50:50), $t_{\mathrm{R} 1} 7.1 \mathrm{~min}(S), t_{\mathrm{R} 2} 7.8$ $\min (R) ;{ }^{31} \mathrm{P}\left\{{ }^{1} \mathrm{H}\right\}$ NMR $\left(202.5 \mathrm{MHz}, \mathrm{CDCl}_{3}\right) \delta 28.0\left(\delta_{\text {lit }} 28.0\right) ;{ }^{9 \mathrm{~b}}{ }^{1} \mathrm{H}$ NMR (500 MHz, $\left.\mathrm{CDCl}_{3}\right) \delta 7.71-7.67(\mathrm{~m}, 2 \mathrm{H}), 7.58-7.48(\mathrm{~m}, 3 \mathrm{H})$, $7.47(\mathrm{dtd}, J=463.1,3.4,1.6,1 \mathrm{H}), 2.04-1.95(\mathrm{~m}, 2 \mathrm{H}), 1.64-1.52(\mathrm{~m}$, $2 \mathrm{H}), 1.48-1.37(\mathrm{~m}, 2 \mathrm{H}), 0.90(\mathrm{td}, J=7.3,1.6,3 \mathrm{H}) ;{ }^{13} \mathrm{C}\left\{{ }^{1} \mathrm{H}\right\} \mathrm{NMR}$ $\left(125.8 \mathrm{MHz}, \mathrm{CDCl}_{3}\right) \delta 132.5$ (d, $\left.J=2.9\right), 131.3(\mathrm{~d}, J=96.4), 130.0$ (d, $J=10.9), 129.0(\mathrm{~d}, J=12.3), 30.2(\mathrm{~d}, J=68.1), 23.8(\mathrm{~d}, J=14.7)$, $23.7(\mathrm{~d}, J=3.7), 13.7$; HRMS (ESI/TOF) $\mathrm{m} / z$ : $[\mathrm{M}+\mathrm{H}]^{+}$Calcd for $\mathrm{C}_{10} \mathrm{H}_{16} \mathrm{OP}$ 183.0939; Found 183.0934.

(R)-tert-Butyl-phenylphosphine Oxide $[(R)-1 \mathrm{~m}] .[\alpha]_{\mathrm{D}}{ }^{25}=+34.4(c$ $=1.32, \mathrm{CHCl}_{3}$, ee $\left.=98 \%\right)$; Chiral HPLC: Kromasil 5-Amycoat column, hexane/ethanol $(85: 15), t_{\mathrm{R} 1} 8.8 \mathrm{~min}(S), t_{\mathrm{R} 2} 11.9 \mathrm{~min}(R)$; ${ }^{31} \mathrm{P}\left\{{ }^{1} \mathrm{H}\right\}$ NMR $\left(202.5 \mathrm{MHz}, \mathrm{CDCl}_{3}\right) \delta 47.5\left(\delta_{\text {lit }} 47.6\right) ;{ }^{9 \mathrm{~b}}{ }^{1} \mathrm{H}$ NMR $\left(500 \mathrm{MHz} \mathrm{CDCl}_{3}\right) \delta 7.71-7.67(\mathrm{~m}, 2 \mathrm{H}), 7.60-7.57(\mathrm{~m}, 1 \mathrm{H}), 7.52-$ $7.50(\mathrm{~m}, 2 \mathrm{H}), 7.04(\mathrm{~d}, J=452.8,1 \mathrm{H}), 1.16(\mathrm{~d}, J=16.6,9 \mathrm{H}) ;{ }^{13} \mathrm{C}\left\{{ }^{1} \mathrm{H}\right\}$ NMR $\left(125.8 \mathrm{MHz}, \mathrm{CDCl}_{3}\right) \delta 132.6(\mathrm{~d}, J=2.7), 131.0(\mathrm{~d}, J=10.0)$, $129.1(\mathrm{~d}, J=90.1), 128.6(\mathrm{~d}, J=11.8), 32.1(\mathrm{~d}, J=69.2), 23.6(\mathrm{~d}, J=$ 2.1); HRMS (ESI/TOF) $m / z:[\mathrm{M}+\mathrm{H}]^{+}$Calcd for $\mathrm{C}_{10} \mathrm{H}_{16} \mathrm{OP}$ 183.0939; Found 183.0936.

(S)-Cyclohexyl-phenylphosphine Oxide $[(S)-1 n] .[\alpha]_{\mathrm{D}}{ }^{25}=-25.3$ $\left(c=1.06, \mathrm{CHCl}_{3}\right.$, ee $\left.=92 \%\right)$; Chiral HPLC: Phenomenex Lux $5 \mu \mathrm{m}$ Cellulose-2 column, hexane/ethanol (50:50), $t_{\mathrm{R} 1} 10.0 \mathrm{~min}(S), t_{\mathrm{R} 2}$ $19.7 \min (R) ;{ }^{31} \mathrm{P}\left\{{ }^{1} \mathrm{H}\right\} \quad \mathrm{NMR}\left(202.5 \mathrm{MHz}, \mathrm{CDCl}_{3}\right) \delta 36.6\left(\delta_{\text {lit }}\right.$ $36.7) ;{ }^{10 \mathrm{~b}}{ }^{1} \mathrm{H}$ NMR $\left(500 \mathrm{MHz}, \mathrm{CDCl}_{3}\right) \delta 7.68-7.64(\mathrm{~m}, 2 \mathrm{H}), 7.58-$ $7.47(\mathrm{~m}, 3 \mathrm{H}), 7.18(\mathrm{~d}, J=446.6,1 \mathrm{H}), 1.93-1.79(\mathrm{~m}, 5 \mathrm{H}), 1.70-1.68$ $(\mathrm{m}, 1 \mathrm{H}), 1.39-1.17(\mathrm{~m}, 5 \mathrm{H}) ;{ }^{13} \mathrm{C}\left\{{ }^{1} \mathrm{H}\right\}$ NMR $\left(125.8 \mathrm{MHz}, \mathrm{CDCl}_{3}\right) \delta$ 132.5 (d, $J=2.8$ ), 130.4 (d, $J=10.4$ ), 130.0 (d, $J=92.9$ ), 128.9 (d, $J$ $=12.0), 38.7(\mathrm{~d}, J=69.7), 26.1(\mathrm{~d}, J=5.3), 26.0(\mathrm{~d}, J=4.9), 25.9(\mathrm{~d}$ $J=1.7$ ), 25.4 (d, $J=1.9$ ), 24.7 (d, $J=2.6$ ); HRMS (ESI/TOF) $m / z$ : $[\mathrm{M}+\mathrm{H}]^{+}$Calcd for $\mathrm{C}_{12} \mathrm{H}_{18}$ OP 209.1095; Found 209.1093.

Gram-Scale Resolution of (2-Methylphenyl)-phenylphosphine Oxide (1a) or tert-Butyl-phenylphosphine Oxide $(1 \mathrm{~m})$ with spiro-TADDOL $[(R, R)-2]$. (2-Methylphenyl)-phenylphosphine Oxide (1a). $2.0 \mathrm{~g}$ (9.3 mmol) of racemic (2-methylphenyl)phenylphosphine oxide $(\mathbf{1 a})$ and $4.7 \mathrm{~g}(9.3 \mathrm{mmol})$ of spiro-TADDOL $[(R, R)-2]$ were dissolved in $28 \mathrm{~mL}$ of hot $2-\mathrm{PrOH}$ using an oil bath as the heat source. The colorless crystalline diastereomeric complex of $(S)$-1a. (spiro-TADDOL), appeared after cooling the mixture to 25 ${ }^{\circ} \mathrm{C}$. After standing at $25{ }^{\circ} \mathrm{C}$ for $3 \mathrm{~h}$, the crystals were separated by filtration and washed $2 \times$ with $2.8 \mathrm{~mL}$ of $2-\mathrm{PrOH}$ to give $5.3 \mathrm{~g}$ (94\%) 
of $(S)-\mathbf{1 a} \cdot(\text { spiro-TADDOL })_{2}$ with a de of $98 \%$. (S)-(2-Methylphenyl)-phenylphosphine oxide $[(S)-1 \mathbf{a}]$ was recovered from the diastereomer by flash column chromatography (silica gel, gradient elution, DCM to DCM-MeOH 95:5) to give $0.92 \mathrm{~g}(92 \%)$ of $(S)$-(2methylphenyl)-phenylphosphine oxide [(S)-1a] with an ee of $98 \%$ (Scheme 3).

tert-Butyl-phenylphosphine Oxide $(1 \mathrm{~m}) .2 .2 \mathrm{~g}(12.1 \mathrm{mmol})$ of racemic tert-butyl-phenylphosphine oxide $(1 \mathrm{~m})$ and $3.1 \mathrm{~g}(6.1 \mathrm{mmol})$ of spiro-TADDOL $[(R, R)-2]$ were dissolved in $18 \mathrm{~mL}$ of hot 2-PrOH using an oil bath as the heat source. The colorless crystalline diastereomeric complex of $(R)-\mathbf{1} \mathbf{m} \cdot($ spiro-TADDOL) appeared after cooling the mixture to $25{ }^{\circ} \mathrm{C}$. After standing at $25{ }^{\circ} \mathrm{C}$ for $3 \mathrm{~h}$, the crystals were separated by filtration and washed $2 \times$ with $1.8 \mathrm{~mL}$ of 2 $\mathrm{PrOH}$ to give $3.6 \mathrm{~g}(87 \%)$ of $(R)-\mathbf{1 m} \cdot($ spiro-TADDOL) with a de of $78 \%$. The diastereomeric complex $(R)-1 \mathrm{~m} \cdot($ spiro-TADDOL) was purified by two recrystallizations from $18 \mathrm{~mL}$ of 2-PrOH according to the procedure described above to afford $2.6 \mathrm{~g}(63 \%)$ of the $(R)-1 \mathbf{m}$. (spiro-TADDOL) with a de of $98 \%$. (R)-tert-Butyl-phenylphosphine oxide $[(R)-\mathbf{1} \mathbf{m}]$ was recovered from the diastereomer by flash column chromatography (silica gel, gradient elution, DCM to DCM-MeOH 95:5) to give $0.66 \mathrm{~g}(60 \%)$ of $(R)$-tert-butyl-phenylphosphine oxide $[(R)-\mathbf{1 m}]$ with an ee of $98 \%$ (Scheme 3 ).

Preparation of (S)-Methyl-(2-methylphenyl)-phenylphosphine Oxide [(S)-3a] via Stereospecific Alkylation (Representative Procedure IV). Under argon atmosphere, $20 \mathrm{mg}$ of $60 \%(\mathrm{w} / \mathrm{w}$ \%) $\mathrm{NaH}$ dispersion (12 $\mathrm{mg}$ of $\mathrm{NaH}, 0.48 \mathrm{mmol}$ ) was washed with anhydrous THF $(3 \times 1.0 \mathrm{~mL})$; then, $1.0 \mathrm{~mL}$ of anhydrous THF was added. To this suspension, $80 \mathrm{mg}(0.37 \mathrm{mmol})$ of $(S)$-(2methylphenyl)-phenylphosphine oxide $[(S)-1 \mathrm{a}$, ee $=98 \%]$ in 1.0 $\mathrm{mL}$ of anhydrous THF was added dropwise over $10 \mathrm{~min}$ at $0{ }^{\circ} \mathrm{C}$, and the reaction mixture was stirred for $45 \mathrm{~min}$ at this temperature. Then, $28 \mu \mathrm{L}(0.44 \mathrm{mmol})$ of $\mathrm{MeI}$ in $1.0 \mathrm{~mL}$ of anhydrous THF was added dropwise over $30 \mathrm{~min}$ at $0{ }^{\circ} \mathrm{C}$. The reaction mixture was allowed to warm to $25^{\circ} \mathrm{C}$, and it was stirred overnight. Then, $1 \mathrm{~mL}$ of saturated $\mathrm{NH}_{4} \mathrm{Cl}$ solution and $1 \mathrm{~mL}$ of water were added. Phases were separated, and the aqueous layer was extracted with EtOAc $(3 \times 1$ $\mathrm{mL})$. The organic layers were combined, dried $\left(\mathrm{Na}_{2} \mathrm{SO}_{4}\right)$, and evaporated. The crude product was purified by flash column chromatography (silica gel, gradient elution, $\mathrm{CHCl}_{3}$ to $\mathrm{CHCl}_{3}-$ $\mathrm{MeOH} 97: 3)$ to give $74 \mathrm{mg}(87 \%)$ of (S)-methyl-(2-methylphenyl)phenylphosphine oxide $[(S)-3 a]$ with an ee of $98 \%$ as a white solid. mp: $104{ }^{\circ} \mathrm{C}\left(\mathrm{mp}_{\text {lit }}: 114{ }^{\circ} \mathrm{C}\right) ;{ }^{50}[\alpha]_{\mathrm{D}}{ }^{25}=-33.0\left(c=1.00, \mathrm{CHCl}_{3}\right.$, ee $=$ $\left.98 \%, S_{\mathrm{P}}\right)\left([\alpha]_{\text {lit }}=-28.2\left(c=1.0, \mathrm{CHCl}_{3}\right.\right.$, ee $\left.\left.=96 \%, S_{\mathrm{P}}\right)\right) ;{ }^{50}$ Chiral HPLC: Kromasil 5-Amycoat column, hexane/ethanol (85:15), $t_{\mathrm{R} 1}$ $10.9 \min (S), t_{\mathrm{R} 2} 13.5 \min (R) ;{ }^{31} \mathrm{P}\left\{{ }^{1} \mathrm{H}\right\} \mathrm{NMR}\left(121.5 \mathrm{MHz}, \mathrm{CDCl}_{3}\right)$ $\delta 31.8\left(\delta_{\text {lit }} 31.4\right) ;{ }^{50}{ }^{1} \mathrm{H}$ NMR $\left(500 \mathrm{MHz}, \mathrm{CDCl}_{3}\right) \delta 7.68-7.61(\mathrm{~m}$, $3 \mathrm{H}), 7.52-7.40(\mathrm{~m}, 4 \mathrm{H}), 7.30-7.21(\mathrm{~m}, 2 \mathrm{H}), 2.36(\mathrm{~s}, 3 \mathrm{H}), 2.03(\mathrm{~d}$, $3 \mathrm{H}, J=13.1) ;{ }^{13} \mathrm{C}\left\{{ }^{1} \mathrm{H}\right\}$ NMR $\left(75.5 \mathrm{MHz}, \mathrm{CDCl}_{3}\right) \delta 142.2(\mathrm{~d}, J=$ 8.3), 134.8 (d, $J=100.1), 132.2(\mathrm{~d}, J=2.8), 132.0(\mathrm{~d}, J=10.3)$, $131.6,131.6(\mathrm{~d}, J=14.6), 130.9(J=$ not visible $), 130.5(\mathrm{~d}, J=10.0)$, 128.7 (d, $J=12.0$ ), 125.6 (d, $J=12.3$ ), 21.4 (d, $J=4.7$ ), 17.3 (d, $J=$ 74.1); HRMS (ESI/TOF) $m / z:[\mathrm{M}+\mathrm{H}]^{+}$Calcd for $\mathrm{C}_{14} \mathrm{H}_{16} \mathrm{OP}$ 231.0939; Found 231.0937.

(S)-Ethyl-(2-methylphenyl)-phenylphosphine Oxide [(S)-3b]. (S)Ethyl-(2-methylphenyl)-phenylphosphine oxide $[(S)-3 \mathbf{b}]$ was prepared according to Representative Procedure IV by reacting $12 \mathrm{mg}$ $(0.48 \mathrm{mmol})$ of $\mathrm{NaH}$ in $1.0 \mathrm{~mL}$ of anhydrous THF with $80 \mathrm{mg}(0.37$ mmol) of $(S)$-(2-methylphenyl)-phenylphosphine oxide [(S)-1a, ee = $98 \%]$ in $1.0 \mathrm{~mL}$ of anhydrous THF and $36 \mu \mathrm{L}(0.44 \mathrm{mmol})$ of EtI in $1.0 \mathrm{~mL}$ of anhydrous THF at $0{ }^{\circ} \mathrm{C}$. The crude product was purified by flash column chromatography (silica gel, gradient elution, $\mathrm{CHCl}_{3}$ to $\left.\mathrm{CHCl}_{3}-\mathrm{MeOH} 97: 3\right)$ to give $72 \mathrm{mg}(80 \%)$ of $(S)$-ethyl-(2methylphenyl)-phenylphosphine oxide $[(S)-3 \mathbf{b}]$ with an ee of $95 \%$ as a white solid. mp $90-92{ }^{\circ} \mathrm{C}\left(\mathrm{mp}_{\mathrm{lit}}: 94-95^{\circ} \mathrm{C}\right) ;^{21 \mathrm{~b}}[\alpha]_{\mathrm{D}}{ }^{25}=-31.0$ $\left(c=1.00, \mathrm{CHCl}_{3}\right.$, ee $\left.=95 \%, S_{\mathrm{P}}\right)\left([\alpha]_{\text {lit }}=+32.6\left(c=1.2, \mathrm{CHCl}_{3}\right.\right.$, ee $=$ $\left.\left.99 \%, R_{\mathrm{p}}\right)\right){ }^{21 \mathrm{~b}}$ Chiral HPLC: Kromasil 5-Amycoat column, hexane/ ethanol (85:15), $t_{\mathrm{R} 1} 8.4 \min (S), t_{\mathrm{R} 2} 12.6 \min (R) .{ }^{31} \mathrm{P}\left\{{ }^{1} \mathrm{H}\right\} \mathrm{NMR}$ $\left(121.5 \mathrm{MHz}, \mathrm{CDCl}_{3}\right) \delta 36.2\left(\delta_{\text {lit }} 35.5\right) ;{ }^{51}{ }^{1} \mathrm{H}$ NMR $(500 \mathrm{MHz}$, $\left.\mathrm{CDCl}_{3}\right) \delta 7.67-7.60(\mathrm{~m}, 3 \mathrm{H}), 7.50-7.39(\mathrm{~m}, 4 \mathrm{H}), 7.30-7.26(\mathrm{~m}$, $1 \mathrm{H}), 7.22-7.20(\mathrm{~m}, 1 \mathrm{H}), 2.43-2.19(\mathrm{~m}, 5 \mathrm{H}), 1.19(\mathrm{dt}, 3 \mathrm{H} J=16.9$,
7.6); ${ }^{13} \mathrm{C}\left\{{ }^{1} \mathrm{H}\right\}$ NMR $\left(75.5 \mathrm{MHz}, \mathrm{CDCl}_{3}\right) \delta 142.7(\mathrm{~d}, J=7.6), 133.7$ (d, $J=96.5), 132.1$ (d, $J=10.2), 132.0$ (d, $J=2.6), 131.6$ (d, $J=$ $11.1), 131.5(\mathrm{~d}, J=3.1), 130.9(\mathrm{~d}, J=9.5), 130.2(J=$ not visible), 128.6 (d, $J=11.6), 125.5$ (d, $J=11.8), 22.7(\mathrm{~d}, J=73.4), 21.5$ (d, $J=$ 4.3), $5.8\left(\mathrm{~d}, J=4.9\right.$ ); HRMS (ESI/TOF) $\mathrm{m} / z:[\mathrm{M}+\mathrm{H}]^{+}$Calcd for $\mathrm{C}_{15} \mathrm{H}_{18} \mathrm{OP}$ 245.1095; Found 245.1085.

(S)-Benzyl-(2-methylphenyl)-phenylphosphine Oxide [(S)-3c]. $(S)$-Benzyl-(2-methylphenyl)phosphine oxide $[(S)-3 \mathbf{c}]$ was prepared according to Representative Procedure IV by reacting $12 \mathrm{mg}(0.48$ $\mathrm{mmol})$ of $\mathrm{NaH}$ in $1.0 \mathrm{~mL}$ of anhydrous THF with $80 \mathrm{mg}(0.37 \mathrm{mmol})$ of $(S)$-(2-methylphenyl)-phenylphosphine oxide [(S)-1a, ee $=98 \%$ ] in $1.0 \mathrm{~mL}$ of anhydrous THF and $53 \mu \mathrm{L}(0.44 \mathrm{mmol})$ of $\mathrm{BnBr}$ in 1.0 $\mathrm{mL}$ of anhydrous THF at $0{ }^{\circ} \mathrm{C}$. The crude product was purified by flash column chromatography (silica gel, gradient elution, $\mathrm{CHCl}_{3}$ to $\left.\mathrm{CHCl}_{3}-\mathrm{MeOH} 95: 5\right)$ to give $86 \mathrm{mg}(76 \%)$ of (S)-benzyl-(2methylphenyl)-phenylphosphine oxide $[(S)-3 \mathrm{c}]$ with an ee of $96 \%$ as a white solid. mp: $167-170{ }^{\circ} \mathrm{C} ;[\alpha]_{\mathrm{D}}{ }^{25}=-84.9\left(c=1.01, \mathrm{CHCl}_{3}\right.$, ee $\left.=96 \%, S_{\mathrm{P}}\right)\left([\alpha]_{\text {lit }}=+29.8\left(c=1, \mathrm{CHCl}_{3}, R_{\mathrm{P}}\right)\right)$; $^{52}$ Chiral HPLC: Phenomenex Lux $5 \mu \mathrm{m}$ Amylose-2 column, hexane/ethanol (85:15), $t_{\mathrm{R} 1} 17.2 \min (S), t_{\mathrm{R} 2} 24.3 \mathrm{~min}(\mathrm{R}) .{ }^{31} \mathrm{P}$ NMR $\left(121.5 \mathrm{MHz}, \mathrm{CDCl}_{3}\right) \delta$ 31.0; ${ }^{1} \mathrm{H}$ NMR (500 MHz, $\left.\mathrm{CDCl}_{3}\right) \delta 7.70-7.66(\mathrm{~m}, 1 \mathrm{H}), 7.51-7.35$ (m, 6H), 7.29-7.17 (m, 5H), 7.09-7.07 (m, 2H), 3.80-3.61 (m, $2 \mathrm{H}), 2.35(\mathrm{~s}, 3 \mathrm{H}) ;{ }^{13} \mathrm{C}\left\{{ }^{1} \mathrm{H}\right\}$ NMR $\left(75.5 \mathrm{MHz}, \mathrm{CDCl}_{3}\right) \delta 143.1(\mathrm{~d}, J=$ 7.7), $133.2(\mathrm{~d}, J=98.6), 132.2(\mathrm{~d}, J=8.7), 132.1,131.7,131.6(\mathrm{~d}, J=$ 7.9), 131.3 (d, $J=7.8), 131.1$ (d, $J=9.5), 130.6(\mathrm{~d}, J=97.6), 130.4$ $(\mathrm{d}, J=5.2), 128.5(\mathrm{~d}, J=11.6), 128.4,126.8(\mathrm{~d}, J=3.0), 125.5(\mathrm{~d}, J=$ 12.0), 37.8 (d, $J=66.7$ ), 21.5 (d, $J=4.2$ ); HRMS (ESI/TOF) $\mathrm{m} / z$ : $[\mathrm{M}+\mathrm{H}]^{+}$Calcd for $\mathrm{C}_{20} \mathrm{H}_{20}$ OP 307.1252; Found 307.1252.

Preparation of (S)-(1-Naphthyl)-(2-methylphenyl)-phenylphosphine Oxide [(S)-3d]. A solution of $43 \mu \mathrm{L}(0.41 \mathrm{mmol})$ of 1 bromonaphthalene, $0.10 \mathrm{~g}(0.74 \mathrm{mmol})$ of anhydrous $\mathrm{K}_{2} \mathrm{CO}_{3}$, and 22 $\mathrm{mg}(0.019 \mathrm{mmol})$ of $\mathrm{Pd}\left(\mathrm{PPh}_{3}\right)_{4}$ in $1.0 \mathrm{~mL}$ of anhydrous toluene was stirred at $25{ }^{\circ} \mathrm{C}$ under argon atmosphere for $30 \mathrm{~min}$. Then, $80 \mathrm{mg}$ $(0.37 \mathrm{mmol})$ of $(S)$-(2-methylphenyl)-phenylphosphine oxide $[(S)$ la, ee $=98 \%]$ in $1.0 \mathrm{~mL}$ of anhydrous toluene was added dropwise. The reaction mixture was stirred at $110^{\circ} \mathrm{C}$ for $22 \mathrm{~h}$ using an oil bath as the heat source. After cooling to $25{ }^{\circ} \mathrm{C}$, it was filtered through a short plug of silica gel, washed with EtOAc, and evaporated. The crude product was purified by flash column chromatography (silica gel, gradient elution, hexane to hexane-EtOAc 20:80) to give $107 \mathrm{mg}$ (85\%) of (S)-(1-naphthyl)-(2-methylphenyl)-phenylphosphine oxide $[(S)-3 \mathrm{~d}]$ with an ee of $88 \%$ as a white solid. mp $87-92^{\circ} \mathrm{C}$; $[\alpha]_{\mathrm{D}}{ }^{25}=$ $-7.8\left(c=1.00, \mathrm{CHCl}_{3}\right.$, ee $\left.=88 \%, S_{\mathrm{p}}\right)\left([\alpha]_{\text {lit }}=-8\left(c=1, \mathrm{CHCl}_{3}\right.\right.$, $\left.\left.S_{\mathrm{P}}\right)\right) ;^{52}$ Chiral HPLC: Kromasil 5-Amycoat column, hexane/ethanol $(80: 20), t_{\mathrm{R} 1} 8.7 \min (R), t_{\mathrm{R} 2} 11.1 \mathrm{~min}(S) ;{ }^{31} \mathrm{P}\left\{{ }^{1} \mathrm{H}\right\} \mathrm{NMR}(121.5$ $\left.\mathrm{MHz}_{\mathrm{CDCl}}\right) \delta 35.6 ;{ }^{1} \mathrm{H} \mathrm{NMR}\left(500 \mathrm{MHz}, \mathrm{CDCl}_{3}\right) \delta 8.72(\mathrm{~d}, 1 \mathrm{H}, J=$ 8.4), 8.00 (d, $1 \mathrm{H}, J=8.1), 7.88(\mathrm{~d}, 1 \mathrm{H}, J=7.9), 7.68-7.64(\mathrm{~m}, 2 \mathrm{H})$, $7.56-7.35(\mathrm{~m}, 7 \mathrm{H}), 7.32-7.26(\mathrm{~m}, 2 \mathrm{H}), 7.07(\mathrm{dt}, 1 \mathrm{H}, J=7.7,3.9)$, 7.03-6.98 (m, 1H), $2.56(\mathrm{~s}, 3 \mathrm{H}) ;{ }^{13} \mathrm{C}\left\{{ }^{1} \mathrm{H}\right\}$ NMR $(125.8 \mathrm{MHz}$, $\left.\mathrm{CDCl}_{3}\right) \delta 143.5(\mathrm{~d}, J=7.9), 134.1(\mathrm{~d}, J=1.8), 134.0,133.6(\mathrm{~d}, J=$ 97.2), 133.4 (d, $J=12.9), 133.2$ (d, $J=2.9), 133.1$ ( $\mathrm{d}, J=11.9$ ), 132.4 (d, $J=9.8), 132.1$ (d, $J=5.5), 132.0(\mathrm{~d}, J=7.6), 131.9$ (d, $J=2.8$ ), $131.0(\mathrm{~d}, J=103.2), 129.1(\mathrm{~d}, J=101.2), 128.8,128.6(\mathrm{~d}, J=12.1)$, 127.9 (d, $J=5.3$ ), 127.4, 126.6, 125.4 (d, $J=12.9$ ), 124.4 (d, $J=$ 14.3), $22.0(\mathrm{~d}, J=4.4)$; HRMS (ESI/TOF) $m / z:[\mathrm{M}+\mathrm{H}]^{+}$Calcd for $\mathrm{C}_{23} \mathrm{H}_{20} \mathrm{OP}$ 343.1252; Found 343.1238.

Preparation of $(R)$-(2-Methylphenyl)-phenylphosphothioic Acid $[(R)-3 e]$. To a solution of $58 \mathrm{mg}(0.27 \mathrm{mmol})$ of $(S)-(2-$ methylphenyl)-phenylphosphine oxide $[(S)-1 \mathrm{a}$, ee $=98 \%]$ in $0.54 \mathrm{~mL}$ of anhydrous THF was added $8.6 \mathrm{mg}(0.27 \mathrm{mmol})$ of sulfur. Using an oil bath, the reaction mixture was heated at $67{ }^{\circ} \mathrm{C}$ under argon atmosphere for $1.5 \mathrm{~h}$; then, the solvent was evaporated. The residue was crystallized from $1.1 \mathrm{~mL}$ of hexane to afford $53 \mathrm{mg}(80 \%)$ of $(R)$ (2-methylphenyl)-phenylphosphothioic acid $[(R)-3 \mathbf{e}]$ with an ee of $>98 \%$ as a white solid. mp: $103-104{ }^{\circ} \mathrm{C} ;[\alpha]_{\mathrm{D}}{ }^{25}=+48.3(c=0.97$, $\mathrm{CHCl}_{3}$, ee $\left.=99 \%, R_{\mathrm{P}}\right) ;{ }^{31} \mathrm{P}\left\{{ }^{1} \mathrm{H}\right\} \operatorname{NMR}\left(202.5 \mathrm{MHz}, \mathrm{CDCl}_{3}\right) \delta 75.3$; ${ }^{1} \mathrm{H}$ NMR $\left(500 \mathrm{MHz}, \mathrm{CDCl}_{3}\right) \delta 7.98(\mathrm{dd}, 1 \mathrm{H}, J=15.2,7.7), 7.80-$ $7.76(\mathrm{~m}, 2 \mathrm{H}), 7.48(\mathrm{dt}, 1 \mathrm{H}, J=7.4,4.5), 7.42-7.38(\mathrm{~m}, 3 \mathrm{H}), 7.29-$ $7.27(\mathrm{~m}, 1 \mathrm{H}), 7.17(\mathrm{t}, 1 \mathrm{H}, J=6.4), 2.32(\mathrm{~s}, 3 \mathrm{H}) ;{ }^{13} \mathrm{C}\left\{{ }^{1} \mathrm{H}\right\}$ NMR $\left(125.8 \mathrm{MHz}, \mathrm{CDCl}_{3}\right) \delta 141.0(\mathrm{~d}, J=11.7), 135.4(\mathrm{~d}, J=108.3), 132.5$ 
(d, $J=11.6), 132.5$ (d, $J=109.3), 132.3(\mathrm{~d}, J=3.0), 132.0(\mathrm{~d}, J=$ 5.9), 131.9 (d, $J=3.4), 131.0$ (d, $J=12.2$ ), 128.5 (d, $J=13.7), 125.7$ $(\mathrm{d}, J=13.4), 21.7(\mathrm{~d}, J=4.9)$; HRMS (ESI/TOF) $m / z:[\mathrm{M}+\mathrm{H}]^{+}$ Calcd for $\mathrm{C}_{13} \mathrm{H}_{14}$ OPS 249.0503; Found 249.0497.

Preparation of (S)-Hydroxymethyl-(2-methylphenyl)-phenylphosphine Oxide [(S)-3f]. To $2.6 \mathrm{~mL}$ of $\mathrm{NaOH}$ solution $(0.05 \mathrm{M})$ were added $61 \mathrm{mg}(0.28 \mathrm{mmol})$ of $(S)$-(2-methylphenyl)phenylphosphine oxide $[(S)-1 \mathrm{a}$, ee $=98 \%]$ and $25 \mu \mathrm{L}(0.34 \mathrm{mmol})$ of $37 \%$ formaldehyde solution at $25{ }^{\circ} \mathrm{C}$. The reaction mixture was heated in an oil bath at $80^{\circ} \mathrm{C}$ for $16 \mathrm{~h}$ and then cooled to $25^{\circ} \mathrm{C}$. Two $\mathrm{mL}$ of DCM was added; the phases were separated, and the aqueous layer was extracted with DCM $(3 \times 2 \mathrm{~mL})$. The organic layers were combined, dried $\left(\mathrm{Na}_{2} \mathrm{SO}_{4}\right)$, and evaporated to give $72 \mathrm{mg}(98 \%)$ of (S)-hydroxymethyl-(2-methylphenyl)-phenylphosphine oxide $[(S)$ 3f] with an ee of $96 \%$ as a white solid. mp: $140-142{ }^{\circ} \mathrm{C}$; $[\alpha]_{\mathrm{D}}{ }^{25}=$ $-42.7\left(c=1.00, \mathrm{CHCl}_{3}\right.$, ee $\left.=96 \%, S_{\mathrm{P}}\right)$; Chiral HPLC: Phenomenex Lux $3 \mu \mathrm{m}$ Cellulose-4 column, hexane/ethanol (50:50), $t_{\mathrm{R} 1} 8.6 \mathrm{~min}$ $(S), t_{\mathrm{R} 2} 9.2 \min (R) ;{ }^{31} \mathrm{P}\left\{{ }^{1} \mathrm{H}\right\} \mathrm{NMR}\left(202.5 \mathrm{MHz}, \mathrm{DMSO}-d_{6}\right) \delta 29.9$; ${ }^{1} \mathrm{H}$ NMR (500 MHz, DMSO- $\left.d_{6}\right) \delta 7.78-7.74(\mathrm{~m}, 1 \mathrm{H}), 7.64-7.44$ $(\mathrm{m}, 6 \mathrm{H}), 7.35-7.26(\mathrm{~m}, 2 \mathrm{H}), 5.76(\mathrm{~s}, 1 \mathrm{H}), 4.34-4.22(\mathrm{~m}, 2 \mathrm{H}), 2.30$ $(\mathrm{s}, 3 \mathrm{H}) ;{ }^{13} \mathrm{C}\left\{{ }^{1} \mathrm{H}\right\}$ NMR $\left(125.8 \mathrm{MHz}\right.$, DMSO- $\left.d_{6}\right) \delta 141.9(\mathrm{~d}, J=7.2)$, 132.7 (d, $J=92.9), 131.9,131.8(\mathrm{~d}, J=9.0), 131.5(\mathrm{~d}, J=6.0), 131.6$, 131.0 (d, $J=9.0$ ), 130.3 (d, $J=93.1$ ), 128.4 (d, $J=11.0), 125.5$ (d, $J$ $=11.8), 60.2(\mathrm{~d}, J=87.3), 20.6(\mathrm{~d}, J=4.2)$; HRMS (ESI/TOF) $\mathrm{m} / z$ : $[\mathrm{M}+\mathrm{H}]^{+}$Calcd for $\mathrm{C}_{14} \mathrm{H}_{16} \mathrm{O}_{2} \mathrm{P}$ 247.0888; Found 247.0884.

Preparation of $\left(S_{\mathrm{P}}\right)-\left[\left(R_{\mathrm{C}}\right)\right.$-Hydroxy(phenyl)methyl]-(2-methylphenyl)-phenylphosphine oxide $\left[\left(S_{\mathrm{P}}, \boldsymbol{R}_{\mathrm{C}}\right)-3 \mathrm{~g}\right]$. To $2.3 \mathrm{~mL}$ of $\mathrm{NaOH}$ solution $(0.05 \mathrm{M})$ were added $54 \mathrm{mg}(25 \mathrm{mmol})$ of $(S)-(2-$ methylphenyl)-phenylphosphine oxide $[(S)-1 \mathrm{a}$, ee $=98 \%]$ and $30 \mu \mathrm{L}$ $(0.30 \mathrm{mmol})$ of benzaldehyde at $25^{\circ} \mathrm{C}$. The reaction mixture was heated in an oil bath at $80^{\circ} \mathrm{C}$ for $16 \mathrm{~h}$ and then cooled to $25^{\circ} \mathrm{C}$. The resulting white suspension was filtered and washed with $2.3 \mathrm{~mL}$ of water and $2.3 \mathrm{~mL}$ of hexane to give $64 \mathrm{mg}(80 \%)$ of $\left(S_{\mathrm{P}}\right)-\left[\left(R_{\mathrm{C}}\right)\right.$ hydroxy(phenyl)methyl]-(2-methylphenyl)-phenylphosphine oxide $\left[\left(S_{\mathrm{P}}, R_{\mathrm{C}}\right)-\mathbf{3 g}\right]$ with an ee of $99 \%$ and de of $95 \%$ as a white solid. mp: $178-179{ }^{\circ} \mathrm{C} ;[\alpha]_{\mathrm{D}}{ }^{25}=-83.3(c=0.28, \mathrm{MeOH}$, ee $=99 \%$, $\left.S_{\mathrm{P}}, R_{\mathrm{C}}\right)$; Chiral HPLC: Phenomenex Lux $5 \mu \mathrm{m}$ Amylose-2 column, hexane/ethanol (85:15), $t_{\mathrm{R} 1} 10.2 \mathrm{~min}\left(R_{\mathrm{P}}, S_{\mathrm{C}}\right), t_{\mathrm{R} 2} 24.5 \mathrm{~min}\left(S_{\mathrm{P}}, R_{\mathrm{C}}\right)$; ${ }^{31} \mathrm{P}\left\{{ }^{1} \mathrm{H}\right\}$ NMR (121.5 MHz, DMSO- $\left.d_{6}\right) \delta 31.6$ (major diastereomer, 97.5\%), 31.3 (minor diastereomer, $2.5 \%) ;{ }^{1} \mathrm{H}$ NMR (500 $\mathrm{MHz}$, DMSO-d $\left.d_{6}\right) \delta 7.96-7.92(\mathrm{~m}, 1 \mathrm{H}), 7.55-7.18(\mathrm{~m}, 13 \mathrm{H}), 6.49(\mathrm{dd}, 1 \mathrm{H}$, $J=17.2,5.9), 5.62-5.60(\mathrm{~m}, 1 \mathrm{H}), 2.18(\mathrm{~s}, 3 \mathrm{H}) ;{ }^{13} \mathrm{C}\left\{{ }^{1} \mathrm{H}\right\} \operatorname{NMR}(75.5$ MHz, DMSO- $\left.d_{6}\right) \delta 143.4(\mathrm{~d}, J=6.8), 138.5,133.8(\mathrm{~d}, J=90.2)$, $133.1(\mathrm{~d}, J=8.7), 132.1,132.0(\mathrm{~d}, J=7.8), 131.8(\mathrm{~d}, J=2.5), 131.6$ (d, $J=8.8), 129.7$ (d, $J=91.5), 128.6(\mathrm{~d}, J=11.1), 128.4(\mathrm{~d}, J=4.5)$, $127.8(\mathrm{~d}, J=1.9), 127.8(\mathrm{~d}, J=2.4), 125.5(\mathrm{~d}, J=11.7), 72.7(\mathrm{~d}, J=$ 85.9), $21.3(\mathrm{~d}, J=3.7)$; HRMS (ESI/TOF) $\mathrm{m} / \mathrm{z}:[\mathrm{M}+\mathrm{H}]^{+}$Calcd for $\mathrm{C}_{20} \mathrm{H}_{20} \mathrm{O}_{2} \mathrm{P}$ 323.1201; Found 323.1197.

X-ray Crystallography. Diastereomeric Complex (S)-1a.(spiro$T A D D O L)$. X-ray quality crystals were prepared by slowly diffusing hexane to the toluene solution of the $(S)-\mathbf{1 a} \cdot($ spiro-TADDOL) diastereomeric complex.

Crystal data: $\mathrm{C}_{34} \mathrm{H}_{34} \mathrm{O}_{4}, \mathrm{C}_{13} \mathrm{H}_{13} \mathrm{OP}$, Fwt.: 722.81, colorless, needle, size: $0.500 \times 0.040 \times 0.040 \mathrm{~mm}$, monoclinic, space group P21, $a=$ 10.553(3) $\AA, b=9.719(3) \AA, c=18.977(6) \AA, \alpha=90^{\circ}, \beta=$ 93.918(7) ${ }^{\circ}, \gamma=90^{\circ}, V=1941.8(11) \AA^{3}, T=294(2) \mathrm{K}, Z=2, F(000)$ $=768, D_{x}=1.236 \mathrm{Mg} / \mathrm{m}^{3}, \mu 0.118 \mathrm{~mm}^{-1}$. A crystal of $(S)-1 \mathrm{a} \cdot($ spiroTADDOL) was mounted on a fiber. Cell parameters were determined by least-squares using $10345\left(2.99^{\circ} \leq \theta \leq 25.275^{\circ}\right)$ reflections. Intensity data were collected on a Rigaku RAXIS-RAPID II diffractometer (monochromator; Mo K $\alpha$ radiation, $\lambda=0.71075 \AA$ ) at $293(2) \mathrm{K}$ in the range of $2.991^{\circ} \leq \theta \leq 21.967^{\circ}$. A total of 20355 reflections were collected of which 5047 were unique $[R$ (int) $=$ $0.2604, R(\sigma)=0.2178]$; intensities of 2392 reflections were greater than $2 \sigma(I)$. Completeness to $\theta=0.997$. A NUMABS absorption correction was applied to the data (the minimum and maximum transmission factors were 0.965396 and 0.995849 ). The structure was solved by direct methods (and subsequent difference syntheses). Anisotropic full-matrix least-squares refinement on $F^{2}$ for all nonhydrogen atoms yielded $R_{1}=0.0889$ and $w R^{2}=0.1329$ for $1332[I>$
$2 \sigma(I)]$ and $R_{1}=0.1869$ and $w R^{2}=0.1668$ for all (5047) intensity data (number of parameters $=481$, goodness-of-fit $=0.960$, the maximum and mean shifts/esd are 0.001 and 0.000 ). The absolute structure parameter is $0.0(3)$ (Friedel coverage: 0.867; Friedel fraction max.: 0.999; Friedel fraction full: 0.999). The maximum and minimum residual electron densities in the final difference map were 0.222 and $-0.219 \mathrm{e} \cdot \AA^{-3}$. The weighting scheme applied was $w=$ $1 /\left[\sigma^{2}\left(F_{\mathrm{o}}{ }^{2}\right)+(0.00390 .0000 P)^{2}+0.0000 P\right]$ where $P=\left(F_{\mathrm{o}}{ }^{2}+2 F_{\mathrm{c}}{ }^{2}\right) / 3$.

$\left(S_{P}\right)-\left[\left(R_{C}\right)-H y d r o x y(\right.$ phenyl)methyl]-(2-methylphenyl)-phenylphosphine Oxide $\left[\left(S_{p}, R_{C}\right)-3 g\right]$. X-ray quality crystals were prepared by the slow evaporation of the solvent from the dichloromethatne solution of $\left(S_{\mathrm{P}}, R_{\mathrm{C}}\right)-3 \mathrm{~g}$.

Crystal data: $\mathrm{C}_{20} \mathrm{H}_{19} \mathrm{O}_{2} \mathrm{P}$, Fwt.: 322.32 , colorless, platelet, size: $0.300 \times 0.100 \times 0.100 \mathrm{~mm}$, orthorhombic, space group $P 212121, a=$ 8.1680(7) $\AA$, $b=9.9573(9) \AA, c=20.1721(17) \AA, \alpha=90^{\circ}, \beta=90^{\circ}, \gamma$ $=90^{\circ}, V=1640.6(2) \AA^{3}, T=294(2) \mathrm{K}, Z=4, F(000)=680, D_{x}=$ $1.305 \mathrm{Mg} / \mathrm{m}^{3}, \mu 0.175 \mathrm{~mm}^{-1}$. A crystal of $\left(S_{\mathrm{P}}, R_{\mathrm{C}}\right)-3 \mathrm{~g}$ was mounted on a fiber. Cell parameters were determined by least-squares using 25498 $\left(3.21^{\circ} \leq \theta \leq 27.475^{\circ}\right)$ reflections. Intensity data were collected on a Rigaku RAXIS-RAPID II diffractometer (monochromator; Mo K $\alpha$ radiation, $\lambda=0.71075 \AA$ ) at $293(2) \mathrm{K}$ in the range of $3.209^{\circ} \leq \theta \leq$ $25.350^{\circ}$. A total of 32784 reflections were collected of which 2996 were unique $[R($ int $)=0.0807, R(\sigma)=0.0367]$; intensities of 2614 reflections were greater than $2 \sigma(I)$. Completeness to $\theta=0.998$. A numerical absorption correction was applied to the data (the minimum and maximum transmission factors were 0.993616 and 0.998669). The structure was solved by direct methods (and subsequent difference syntheses). Anisotropic full-matrix least-squares refinement on $F^{2}$ for all non-hydrogen atoms yielded $R_{1}=0.0500$ and $w R^{2}=0.0854$ for $1332[I>2 \sigma(I)]$ and $R_{1}=0.0620$ and $w R^{2}=0.0893$ for all (2996) intensity data (number of parameters $=210$, goodnessof-fit $=1.122$, the maximum and mean shifts/esd are 0.000 and $0.000)$. The absolute structure parameter is 0.05(4) (Friedel coverage: 0.725; Friedel fraction max.: 1.000; Friedel fraction full: 1.000 ). The maximum and minimum residual electron densities in the final difference map were 0.209 and $-0.196 \mathrm{e} \cdot \AA^{-3}$. The weighting scheme applied was $w=1 /\left[\sigma^{2}\left(F_{\mathrm{o}}{ }^{2}\right)+(0.03550 .2831 P)^{2}+0.2831 P\right]$ where $P=\left(F_{\mathrm{o}}^{2}+2 F_{\mathrm{c}}^{2}\right) / 3$. The crystallographic data are in Table S6.

\section{ASSOCIATED CONTENT}

\section{Supporting Information}

The Supporting Information is available free of charge at https://pubs.acs.org/doi/10.1021/acs.joc.1c01364.

Conditions and results of the resolution experiments; optical rotation values $[\alpha]$ of secondary phosphine oxides (1) and the assignation of their absolute configuration; X-ray measurements; NMR spectra; HPLC traces (PDF)

\section{Accession Codes}

CCDC 2081817 and 2081818 contain the supplementary crystallographic data for this paper. These data can be obtained free of charge via www.ccdc.cam.ac.uk/data_request/cif, or by emailing data_request@ccdc.cam.ac.uk, or by contacting The Cambridge Crystallographic Data Centre, 12 Union Road, Cambridge CB2 1EZ, UK; fax: +44 1223336033.

\section{AUTHOR INFORMATION}

\section{Corresponding Author}

Péter Bagi - Department of Organic Chemistry and Technology, Budapest University of Technology and Economics, H-1111 Budapest, Hungary; (1) orcid.org/00000002-9043-6435; Email: bagi.peter@vbk.bme.hu 


\section{Authors}

Bence Varga - Department of Organic Chemistry and Technology, Budapest University of Technology and Economics, H-1111 Budapest, Hungary

Péter Szemesi - Department of Organic Chemistry and Technology, Budapest University of Technology and Economics, H-1111 Budapest, Hungary; Gedeon Richter Plc., H-1475 Budapest, Hungary

Petra Nagy - Department of Organic Chemistry and Technology, Budapest University of Technology and Economics, H-1111 Budapest, Hungary

Réka Herbay - Department of Organic Chemistry and Technology, Budapest University of Technology and Economics, H-1111 Budapest, Hungary

Tamás Holczbauer - Center for Structural Science, Chemical Crystallography Research Laboratory and Institute for Organic Chemistry, Research Centre for Natural Sciences, $H$ 1519 Budapest, Hungary

Elemér Fogassy - Department of Organic Chemistry and Technology, Budapest University of Technology and Economics, H-1111 Budapest, Hungary

György Keglevich - Department of Organic Chemistry and Technology, Budapest University of Technology and Economics, H-1111 Budapest, Hungary; 이이. orcid.org/00000002-5366-472X

Complete contact information is available at: https://pubs.acs.org/10.1021/acs.joc.1c01364

\section{Notes}

The authors declare no competing financial interest.

\section{ACKNOWLEDGMENTS}

This research was funded by the New National Excellence Program of the Ministry of Human Capacities (Grant No.: UNKP-20-3-II-BME-282). T.H. is grateful for the support of the National Research, Development and Innovation OfficeNKFIH (Grant Nos. PD 128504 and K 124544).

\section{REFERENCES}

(1) (a) Börner, A. Phosphorus Ligands in Asymmetric Catalysis; WileyVCH: Weinheim, 2008. (b) Grabulosa, A. P-Stereogenic Ligands in Enantioselective Catalysis; The Royal Society of Chemistry: Cambridge, 2010. (c) Kamer, P. C. J., Van Leeuwen, P. W. N. M., Eds. Phosphorus(III)Ligands in Homogeneous Catalysis: Design and Synthesis; New York: John Wiley \& Sons, 2012. (d) Imamoto, T. Searching for Practically Useful P-Chirogenic Phosphine Ligands. Chem. Rec. 2016, 16, 2659-2673.

(2) (a) Benaglia, M.; Rossi, S. Chiral Phosphine Oxides in PresentDay Organocatalysis. Org. Biomol. Chem. 2010, 8, 3824-3830. (b) Golandaj, A.; Ahmad, A.; Ramjugernath, D. Phosphonium Salts in Asymmetric Catalysis: A Journey in a Decade's Extensive Research Work. Adv. Synth. Catal. 2017, 359, 3676-3706. (c) Guo, H.; Fan, Y. C.; Sun, Z.; Wu, Y.; Kwon, O. Phosphine Organocatalysis. Chem. Rev. 2018, 118, 10049-10293. (d) Ni, H.; Chan, W.-L.; Lu, Y. PhosphineCatalyzed Asymmetric Organic Reactions. Chem. Rev. 2018, 118, 9344-9411. (e) Ayad, T.; Gernet, A.; Pirat, J.-L.; Virieux, D. Enantioselective Reactions Catalyzed by Phosphine Oxides. Tetrahedron 2019, 75, 4385-4418.

(3) (a) Pradere, U.; Garnier-Amblard, E. C.; Coats, S. J.; Amblard, F.; Schinazi, R. F. Synthesis of Nucleoside Phosphate and Phosphonate Prodrugs. Chem. Rev. 2014, 114, 9154-9218. (b) Mehellou, Y.; Rattan, H. S.; Balzarini, J. The ProTide Prodrug Technology: From the Concept to the Clinic. J. Med. Chem. 2018, 61, 2211-2226. (c) Bellingham, R.; Borrett, G.; Bret, G.; Choudary, B.; Colclough, D.; Hayes, J.; Hayler, J.; Hodnett, N.; Ironmonger, A.;
Ochen, A.; Pascoe, D.; Richardson, J.; Vit, E.; Alexandre, F. R.; Caillet, C.; Amador, A.; Bot, S.; Bonaric, S.; Da Costa, D.; Lioure, M. P.; Roland, A.; Rosinovsky, E.; Parsy, C.; Dousson, C. B. Development and Scale-Up of a Manufacturing Route for the Non-Nucleoside Reverse Transcriptase Inhibitor GSK2248761A (IDX-899): Synthesis of an Advanced Key Chiral Intermediate. Org. Process Res. Dev. 2018, 22, 200-206

(4) (a) Dutartre, M.; Bayardon, J.; Jugé, S. Applications and Stereoselective Syntheses of P-Chirogenic Phosphorus Compounds. Chem. Soc. Rev. 2016, 45, 5771-5794. (b) Chrzanowski, J.; Krasowska, D.; Drabowicz, J. Synthesis of Optically Active Tertiary Phosphine Oxides: A Historical Overview and the Latest Advances. Heteroat. Chem. 2018, 29, No. e21476. (c) Lemouzy, S.; Giordano, L.; Hérault, D.; Buono, G. Introducing Chirality at Phosphorus Atoms: An Update on the Recent Synthetic Strategies for the Preparation of Optically Pure P-Stereogenic Molecules. Eur. J. Org. Chem. 2020, 2020, 3351-3366. (d) Cui, Y. M.; Lin, Y.; Xu, L. W. Catalytic Synthesis of Chiral Organoheteroatom Compounds of Silicon, Phosphorus, and Sulfur via Asymmetric Transition Metal-Catalyzed C-H Functionalization. Coord. Chem. Rev. 2017, 330, 37-52. (e) Lin, Y.; Ma, W. Y.; Sun, Q. Y.; Cui, Y. M.; Xu, L. W. Catalytic Synthesis of Chiral Phosphole Oxides via Desymmetric C-H Arylation of o -Bromoaryl Phosphine Oxides. Synlett 2017, 28 (12), 14321436. (f) Ye, X.; Peng, L.; Bao, X.; Tan, C.-H.; Wang, H. Recent Developments in Highly Efficient Construction of P-Stereogenic Centers. Green Synth. Catal. 2021, 2 (1), 6-18.

(5) Ackermann, L. Air- and Moisture-Stable Secondary Phosphine Oxides as Preligands in Catalysis. Synthesis 2006, 2006, 1557-1571.

(6) (a) Christiansen, A.; Li, C.; Garland, M.; Selent, D.; Ludwig, R.; Spannenberg, A.; Baumann, W.; Franke, R.; Börner, A. On the Tautomerism of Secondary Phosphane Oxides. Eur. J. Org. Chem. 2010, 2010, 2733-2741. (b) Janesko, B. G.; Fisher, H. C.; Bridle, M. J.; Montchamp, J.-L. $\mathrm{P}(=\mathrm{O}) \mathrm{H}$ to $\mathrm{P}-\mathrm{OH}$ Tautomerism: A Theoretical and Experimental Study. J. Org. Chem. 2015, 80, 10025-10032. (c) Vincze, D.; Ábrányi-Balogh, P.; Bagi, P.; Keglevich, G. A Mechanistic Study on the Tautomerism of $\mathrm{H}$ Phosphonates, H-Phosphinates and Secondary Phosphine Oxides. Molecules 2019, 24, 3859.

(7) (a) Shaikh, T. M.; Weng, C.-M.; Hong, F.-E. Secondary Phosphine Oxides: Versatile Ligands in Transition Metal-Catalyzed Cross-Coupling Reactions. Coord. Chem. Rev. 2012, 256, 771-803. (b) Achard, T. Advances in Homogeneous Catalysis Using Secondary Phosphine Oxides (SPOs): Pre-Ligands for Metal Complexes. Chimia 2016, 70, 8-19. (c) Gallen, A.; Riera, A.; Verdaguer, X.; Grabulosa, A. Coordination Chemistry and Catalysis with Secondary Phosphine Oxides. Catal. Sci. Technol. 2019, 9, 5504-5561.

(8) Glueck, D. Asymmetric Synthesis of P-Stereogenic Secondary Phosphine Oxides (SPOs). Synthesis 2021, DOI: 10.1055/a-15820169.

(9) (a) Leyris, A.; Bigeault, J.; Nuel, D.; Giordano, L.; Buono, G. Enantioselective Synthesis of Secondary Phosphine Oxides from (RP)-(-)-Menthyl Hydrogenophenylphosphinate. Tetrahedron Lett. 2007, 48, 5247-5250. (b) Xu, Q.; Zhao, C.-Q.; Han, L.-B. Stereospecific Nucleophilic Substitution of Optically Pure HPhosphinates: A General Way for the Preparation of Chiral PStereogenic Phosphine Oxides. J. Am. Chem. Soc. 2008, 130, 1264812655. (c) Gatineau, D.; Nguyen, D. H.; Hérault, D.; Vanthuyne, N.; Leclaire, J.; Giordano, L.; Buono, G. H-Adamantylphosphinates as Universal Precursors of P-Stereogenic Compounds. J. Org. Chem. 2015, 80, 4132-4141.

(10) (a) Leyris, A.; Nuel, D.; Giordano, L.; Achard, M.; Buono, G. Enantioselective Synthesis of Both Enantiomers of Tert-Butylphenylphosphine Oxide from (S)-Prolinol. Tetrahedron Lett. 2005, 46, 8677-8680. (b) Copey, L.; Jean-Gérard, L.; Andrioletti, B.; Framery, E. Synthesis of P-Stereogenic Secondary Phosphine Oxides Using $\alpha$ d-Glucosamine as a Chiral Precursor. Tetrahedron Lett. 2016, 57, 543-545. (c) Han, Z. S.; Wu, H.; Xu, Y.; Zhang, Y.; Qu, B.; Li, Z.; Caldwell, D. R.; Fandrick, K. R.; Zhang, L.; Roschangar, F.; Song, J. J.; Senanayake, C. H. General and Stereoselective Method for the 
Synthesis of Sterically Congested and Structurally Diverse P -Stereogenic Secondary Phosphine Oxides. Org. Lett. 2017, 19, 1796-1799. (d) Li, S.-G.; Yuan, M.; Topic, F.; Han, Z. S.; Senanayake, C. H.; Tsantrizos, Y. S. Asymmetric Library Synthesis of P-Chiral t -Butyl-Substituted Secondary and Tertiary Phosphine Oxides. J. Org. Chem. 2019, 84, 7291-7302.

(11) (a) Holt, J.; Maj, A. M.; Schudde, E. P.; Pietrusiewicz, K. M.; Sieroń, L.; Wieczorek, W.; Jerphagnon, T.; Arends, I. W. C. E.; Hanefeld, U.; Minnaard, A. J. On the Resolution of Secondary Phosphine Oxides via Diastereomeric Complex Formation: The Case of Tert-Butylphenylphosphine Oxide. Synthesis 2009, 2009, 20612065. (b) Rajendran, K. V.; Gilheany, D. G. Simple Unprecedented Conversion of Phosphine Oxides and Sulfides to Phosphine Boranes Using Sodium Borohydride. Chem. Commun. 2012, 48, 817-819.

(12) (a) Zhang, Y.; He, H.; Wang, Q.; Cai, Q. Asymmetric Synthesis of Chiral P-Stereogenic Triaryl Phosphine Oxides via Pd-Catalyzed Kinetic Arylation of Diaryl Phosphine Oxides. Tetrahedron Lett. 2016, 57, 5308-5311. (b) Beaud, R.; Phipps, R. J.; Gaunt, M. J. Enantioselective $\mathrm{Cu}$-Catalyzed Arylation of Secondary Phosphine Oxides with Diaryliodonium Salts toward the Synthesis of P-Chiral Phosphines. J. Am. Chem. Soc. 2016, 138, 13183-13186. (c) Dai, Q.; Li, W.; Li, Z.; Zhang, J. P-Chiral Phosphines Enabled by Palladium/ Xiao-Phos-Catalyzed Asymmetric P-C Cross-Coupling of Secondary Phosphine Oxides and Aryl Bromides. J. Am. Chem. Soc. 2019, 141, 20556-20564. (d) Liu, X.-T.; Zhang, Y.-Q.; Han, X.-Y.; Sun, S.-P.; Zhang, Q.-W. Ni-Catalyzed Asymmetric Allylation of Secondary Phosphine Oxides. J. Am. Chem. Soc. 2019, 141, 16584-16589. (e) Dai, Q.; Liu, L.; Qian, Y.; Li, W.; Zhang, J. Construction of PChiral Alkenylphosphine Oxides through Highly Chemo-, Regio-, and Enantioselective Hydrophosphinylation of Alkynes. Angew. Chem., Int. Ed. 2020, 59, 20645-20650.

(13) Qiu, H.; Dai, Q.; He, J.; Li, W.; Zhang, J. Access to P -Chiral Sec - and Tert -Phosphine Oxides Enabled by Le-Phos-Catalyzed Asymmetric Kinetic Resolution. Chem. Sci. 2020, 11, 9983-9988.

(14) (a) Haynes, R. K.; Freeman, R. N.; Mitchell, C. R.; Vonwiller, S. C. Preparation of Enantiomerically Pure Tertiary Phosphine Oxides from, and Assay of Enantiomeric Purity with, (Rp)- and (Sp)-TertButylphenylphosphinothioic Acids. J. Org. Chem. 1994, 59, 29192921. (b) Haynes, R. K.; Au-Yeung, T.-L. L.; Chan, W.-K. K.; Lam, W.-L. L.; Li, Z.-Y. Y.; Yeung, L.-L. L.; Chan, A. S. C. C.; Li, P.; Koen, M.; Mitchell, C. R.; Vonwiller, S. C. Reaction of Metallated TertButyl(Phenyl)Phosphane Oxide with Electrophiles as a Route to Functionalized Tertiary Phosphane Oxides: Alkylation Reactions. Eur. J. Org. Chem. 2000, 2000, 3205-3216.

(15) Stankevič, M.; Pietrusiewicz, K. M. Resolution and Stereochemistry of Tert-Butylphenylphosphinous Acid-Borane. J. Org. Chem. 2007, 72, 816-822.

(16) (a) Harger, M. J. P. Chemical Shift Non-Equivalence of Enantiomers in the Proton Magnetic Resonance Spectra of Partly Resolved Phosphinothioic Acids. J. Chem. Soc., Perkin Trans. 2 1978, No. 4, 326-331. (b) Skrzypczynski, Z.; Michalski, J. Stereoselective Synthesis and Stereochemistry of Optically Active Tert-Butylphenylphosphine Sulfide. J. Org. Chem. 1988, 53, 4549-4551. (c) Kobayashi, Y.; Handa, H.; Maeda, J.; Saigo, K. Factors Determining the Pattern of a Hydrogen-Bonding Network in the Diastereomeric Salts of 1Arylethylamines with Enantiopure P-Chiral Acids. Chirality 2008, 20, 577-584. (d) Drabowicz, J.; Pokora-Sobczak, P.; Zając, A.; WachPanfilow, P. A New Procedure for the Synthesis of Optically Active $t$ -Butylphenylphosphinothioic Acid. Heteroat. Chem. 2014, 25, 674677. (e) Stankevič, M.; Pietrusiewicz, K. M. An Efficient Resolution of Phosphinous Acid-Boranes. Tetrahedron: Asymmetry 2007, 18, 552556.

(17) Gallen, A.; Orgué, S.; Muller, G.; Escudero-Adán, E. C.; Riera, A.; Verdaguer, X.; Grabulosa, A. Synthesis and Coordination Chemistry of Enantiopure: $\mathrm{T}-\mathrm{BuMeP}(\mathrm{O}) \mathrm{H}$. Dalton Trans. 2018, 47, 5366-5379.

(18) (a) Jiang, X.; Minnaard, A. J.; Hessen, B.; Feringa, B. L.; Duchateau, A. L. L.; Andrien, J. G. O.; Boogers, J. A. F.; de Vries, J. G. Application of Monodentate Secondary Phosphine Oxides, a New
Class of Chiral Ligands, in $\operatorname{Ir}(\mathrm{I})$-Catalyzed Asymmetric Imine Hydrogenation. Org. Lett. 2003, 5, 1503-1506. (b) Jiang, X.; van den Berg, M.; Minnaard, A. J.; Feringa, B. L.; de Vries, J. G. The Application of Monodentate Secondary Phosphine Oxide Ligands in Rhodium- and Iridium-Catalyzed Asymmetric Hydrogenation. Tetrahedron: Asymmetry 2004, 15, 2223-2229. (c) Bigeault, J.; Giordano, L.; Buono, G. [2 + 1] Cycloadditions of Terminal Alkynes to Norbornene Derivatives Catalyzed by Palladium Complexes with Phosphinous Acid Ligands. Angew. Chem., Int. Ed. 2005, 44, 47534757.

(19) Drabowicz, J.; Łyżwa, P.; Omelańczuk, J.; Pietrusiewicz, K. M.; Mikołajczyk, M. New Procedures for the Resolution of Chiral TertButylphenylphosphine Oxide and Some of Its Reactions. Tetrahedron: Asymmetry 1999, 10, 2757-2763.

(20) Kortmann, F. A.; Chang, M.-C.; Otten, E.; Couzijn, E. P. A.; Lutz, M.; Minnaard, A. J. Consecutive Dynamic Resolutions of Phosphine Oxides. Chem. Sci. 2014, 5, 1322-1327.

(21) (a) Bagi, P.; Ujj, V.; Czugler, M.; Fogassy, E.; Keglevich, G. Resolution of P-Stereogenic P-Heterocycles via the Formation of Diastereomeric Molecular and Coordination Complexes (a Review). Dalton Trans. 2016, 45, 1823-1842. (b) Bagi, P.; Varga, B.; Szilágyi, A.; Karaghiosoff, K.; Czugler, M.; Fogassy, E.; Keglevich, G. The Resolution of Acyclic P -Stereogenic Phosphine Oxides via the Formation of Diastereomeric Complexes: A Case Study on Ethyl-(2Methylphenyl)-Phenylphosphine Oxide. Chirality 2018, 30, 509-522. (c) Varga, B.; Herbay, R.; Székely, G.; Holczbauer, T.; Madarász, J.; Mátravölgyi, B.; Fogassy, E.; Keglevich, G.; Bagi, P. Scalable Enantiomeric Separation of Dialkyl-Arylphosphine Oxides Based on Host-Guest Complexation with TADDOL-Derivatives, and Their Recovery. Eur. J. Org. Chem. 2020, 2020, 1840-1852. (d) Varga, B.; Bagi, P. Preparation of Enantiomerically Enriched P -Stereogenic Dialkyl-Arylphosphine Oxides via Coordination Mediated Optical Resolution. Symmetry 2020, 12, 215.

(22) (a) Hoge, B.; Garcia, P.; Willner, H.; Oberhammer, H. Bis(Trifluoromethyl)Phosphinous Acid (CF3)2P-O-H: An Example of a Thermally Stable Phosphinous Acid - Synthesis, Gas-Phase Structure, and Rotational Isomers. Chem. - Eur. J. 2006, 12, 35673574. (b) Kurscheid, B.; Wiebe, W.; Neumann, B.; Stammler, H.-G.; Hoge, B. Investigations of the Tautomeric Equilibria between Phosphane Oxides and Their Corresponding Phosphinous Acids Bearing Electron-Withdrawing Perfluoroaryl Groups. Eur. J. Inorg. Chem. 2011, 2011, 5523-5529.

(23) Petit, C.; Favre-Réguillon, A.; Mignani, G.; Lemaire, M. A Straightforward Synthesis of Unsymmetrical Secondary Phosphine Boranes. Green Chem. 2010, 12, 326-333.

(24) Trost, B. M.; Spohr, S. M.; Rolka, A. B.; Kalnmals, C. A. Desymmetrization of Phosphinic Acids via Pd-Catalyzed Asymmetric Allylic Alkylation: Rapid Access to P-Chiral Phosphinates. J. Am. Chem. Soc. 2019, 141, 14098-14103.

(25) Macrae, C. F.; Sovago, I.; Cottrell, S. J.; Galek, P. T. A.; McCabe, P.; Pidcock, E.; Platings, M.; Shields, G. P.; Stevens, J. S.; Towler, M.; Wood, P. A. Mercury 4.0: From Visualization to Analysis, Design and Prediction. J. Appl. Crystallogr. 2020, 53, 226-235.

(26) Spackman, M. A.; Jayatilaka, D. Hirshfeld Surface Analysis. CrystEngComm 2009, 11, 19-32.

(27) McKinnon, J. J.; Spackman, M. A.; Mitchell, A. S. Novel Tools for Visualizing and Exploring Intermolecular Interactions in Molecular Crystals. Acta Crystallogr., Sect. B: Struct. Sci. 2004, 60, 627-668.

(28) Holz, J.; Jiao, H.; Gandelman, M.; Börner, A. About the Inversion Barriers of P-Chirogenic Triaryl-Substituted Phosphanes. Eur. J. Org. Chem. 2018, 2018, 2984-2994.

(29) Nie, S.-Z.; Zhou, Z.-Y.; Wang, J.-P.; Yan, H.; Wen, J.-H.; Ye, J.J.; Cui, Y.-Y.; Zhao, C.-Q. Nonepimerizing Alkylation of H-P Species to Stereospecifically Generate P-Stereogenic Phosphine Oxides: A Shortcut to Bidentate Tertiary Phosphine Ligands. J. Org. Chem. 2017, 82, 9425-9434.

(30) (a) Jablonkai, E.; Keglevich, G. P-C Bond Formation by Coupling Reactions Utilizing $>\mathrm{P}(\mathrm{O}) \mathrm{H}$ Species as the Reagents. Curr. Org. Synth. 2014, 11, 429-453. (b) Henyecz, R.; Keglevich, G. New 
Developments on the Hirao Reactions, Especially from "Green" Point of View. Curr. Org. Synth. 2019, 16, 523-545.

(31) (a) Bloomfield, A. J.; Herzon, S. B. Room Temperature, Palladium-Mediated P-Arylation of Secondary Phosphine Oxides. Org. Lett. 2012, 14, 4370-4373. (b) Chrzanowski, J.; Krasowska, D.; Urbaniak, M.; Sieroń, L.; Pokora-Sobczak, P.; Demchuk, O. M.; Drabowicz, J. Synthesis of Enantioenriched Aryl- Tert -Butylphenylphosphine Oxides via Cross-Coupling Reactions of Tert -Butylphenylphosphine Oxide with Aryl Halides. Eur. J. Org. Chem. 2018, 2018, 4614-4627.

(32) Zhang, H.; Sun, Y. M.; Yao, L.; Ji, S. Y.; Zhao, C. Q.; Han, L. B. Stereogenic Phosphorus-Induced Diastereoselective Formation of Chiral Carbon during Nucleophilic Addition of Chiral H-P Species to Aldehydes or Ketones. Chem. - Asian J. 2014, 9, 1329-1333.

(33) Nolla-Saltiel, R.; Geer, A. M.; Taylor, L. J.; Churchill, O.; Davies, E. S.; Lewis, W.; Blake, A. J.; Kays, D. L. Hydrophosphination of Activated Alkenes by a Cobalt(I) Pincer Complex. Adv. Synth. Catal. 2020, 362 (15), 3148-3157.

(34) Haynes, R. K.; Lam, W. W.-L.; Yeung, L. Stereoselective Preparation of Functionalized Tertiary P-Chiral Phosphine Oxides by Nucleophilic Addition of Lithiated Tert-Butylphenylphosphine Oxide to Carbonyl Compounds. Tetrahedron Lett. 1996, 37, 4729-4732.

(35) Beck, A. K.; Bastani, B.; Plattner, D. A.; Petter, W.; Seebach, D.; Braunschweiger, H.; Gysi, P.; Lavecchia, L. Large-Scale Preparation of Alpha,Alpha,Alpha,Alpha-Tetraaryl-1,3-Dioxolane-4,5-Dimethanols (TADDOL) - Versatile Auxiliaries for EPC Synthesis and Its SolidState Structure. Chimia 1991, 45, 238-244.

(36) Legrand, S.; Luukinen, H.; Isaksson, R.; Kilpeläinen, I.; Lindström, M.; Nicholls, I. A.; Unelius, C. R. Synthesis, NMR Conformational Studies and Host-Guest Behaviour of New

(+)-Tartaric Acid Derivatives. Tetrahedron: Asymmetry 2005, 16 (3), 635-640.

(37) Armarego, W. L. F. Purification of Laboratory Chemicals, 8th ed.; Butterworth-Heinemann: Oxford, 2017.

(38) CrystalClear SM 1.4.0; Rigaku/MSC Inc., 2008.

(39) Higashi, T. NUMABS, rev. 2002; Rigaku/MSC Inc., 1998.

(40) (a) Sheldrick, G. M. A Short History of SHELX. Acta Crystallogr., Sect. A: Found. Crystallogr. 2008, 64 (1), 112-122. (b) Sheldrick, G. M. Crystal Structure Refinement with SHELXL. Acta Crystallogr., Sect. C: Struct. Chem. 2015, 71 (1), 3-8.

(41) Burla, M. C.; Caliandro, R.; Carrozzini, B.; Cascarano, G. L.; Cuocci, C.; Giacovazzo, C.; Mallamo, M.; Mazzone, A.; Polidori, G. Crystal Structure Determination and Refinement via SIR2014. J. Appl. Crystallogr. 2015, 48 (1), 306-309.

(42) Spek, A. L. Structure Validation in Chemical Crystallography. Acta Crystallogr., Sect. D: Biol. Crystallogr. 2009, 65 (2), 148-155.

(43) (a) Macrae, C. F.; Edgington, P. R.; McCabe, P.; Pidcock, E.; Shields, G. P.; Taylor, R.; Towler, M.; van de Streek, J. Mercury: Visualization and Analysis of Crystal Structures. J. Appl. Crystallogr. 2006, 39 (3), 453-457. (b) van der Sluis, P.; Spek, A. L. BYPASS: An Effective Method for the Refinement of Crystal Structures Containing Disordered Solvent Regions. Acta Crystallogr., Sect. A: Found. Crystallogr. 1990, 46 (3), 194-201. (c) Kitaigorodsky, A. I. Molecular Crystals and Molecules; Academic Press: New York, 2012.

(44) (a) Spackman, M. A.; Jayatilaka, D. Hirshfeld Surface Analysis. CrystEngComm 2009, 11 (1), 19-32. (b) Thomas, S. P.; Spackman, P. R.; Jayatilaka, D.; Spackman, M. A. Accurate Lattice Energies for Molecular Crystals from Experimental Crystal Structures. J. Chem. Theory Comput. 2018, 14 (3), 1614-1623.

(45) Shriver, D. F.; Drezdzon, M. A. The Manipulation of AirSensitive Compounds, 2nd ed.; Wiley \& Sons: New York, 1986.

(46) Oliana, M.; King, F.; Horton, P. N.; Hursthouse, M. B.; Hii, K. K. M. Practical Synthesis of Chiral Vinylphosphine Oxides by Direct Nucleophilic Substitution. Stereodivergent Synthesis of Aminophosphine Ligands. J. Org. Chem. 2006, 71, 2472-2479.

(47) Jablonkai, E.; Keglevich, G. Catalyst-Free P-C Coupling Reactions of Halobenzoic Acids and Secondary Phosphine Oxides under Microwave Irradiation in Water. Tetrahedron Lett. 2015, 56, $1638-1640$
(48) Castoldi, L.; Rajkiewicz, A. A.; Olofsson, B. Transition MetalFree and Regioselective Vinylation of Phosphine Oxides and $\mathrm{H}$ -Phosphinates with VBX Reagents. Chem. Commun. 2020, 56, 1438914392.

(49) Dziuba, K.; Lubańska, M.; Pietrusiewicz, K. M. Enantiodivergent Synthesis of Both PAMPO Enantiomers Using 1 -Menthyl Chloroacetate and Stereomutation at $\mathrm{P}$ in Classical Quaternisation Reactions. Synthesis 2020, 52, 909-916.

(50) Adams, H.; Collins, R. C.; Jones, S.; Warner, C. J. A. Enantioselective Preparation of P -Chiral Phosphine Oxides. Org. Lett. 2011, 13, 6576-6579.

(51) Nikitin, K.; Rajendran, K. V.; Müller-Bunz, H.; Gilheany, D. G. Turning Regioselectivity into Stereoselectivity: Efficient Dual Resolution of P-Stereogenic Phosphine Oxides through Bifurcation of the Reaction Pathway of a Common Intermediate. Angew. Chem., Int. Ed. 2014, 53, 1906-1909.

(52) Chookiewicz, W.; Jore, D.; Wodzki, W. Optically Active Phosphines: New Synthetic Approach. Tetrahedron Lett. 1979, 20, $1069-1072$. 